\title{
On the Measurement of Polarisation:
} A questionnaire study

\author{
Yoram Amiel Frank Cowell \\ Ruppin Academic Center London School of Economics \\ Xavier Ramos \\ $U A B$ and $I Z A$
}

September 2007 


\begin{abstract}
Starting from the axiomatisation of polarisation contained in Esteban and Ray (1994) and Chakravarty and Majumdar (2001) we investigate whether people's perceptions of income polarisation is consistent with the key axioms. This is carried out using a questionnaire-experimental approach that combines both paper questionnaires and on-line interactive techniques. The responses suggest that important axioms which serve to differentiate polarisation from inequality - e.g. increased bipolarisation - as well as other distinctive features of polarisation, i.e. the non-monotonous behaviour attributed to polarisation, are not widely accepted.
\end{abstract}

- Acknowledgements. Xavier Ramos aknowledges financial support from the Spanish Ministry of Eduaction and Science project SEC2002-10688E. We thank Maria Cervini for outstanding research assistance. We also thank Michael Brooks, Paul Blacklow, Elias Khalil, Nathalie McCaughey, Vai-Lam Mui..Carlos Troncoso, Eugenia Plá, Gastón Chaves, Gemma Francés, Hèctor Sala, Jaime Amoroso, José Alonso, María Cervini, Maria Cubel, Oriol Roca, Raúl Cervini, Rosa Martínez, Sara Ayllón, Olga Cantó, Coral del Río, Carlos Gradín, Giovanni Ko, Nazan Susam, Artur Colom and Cristina Blanco who helped to organise the questionnaires for us in various institutions. We are very grateful for comments from Joan Esteban, Debraj Ray and Rafael Salas.

- Keywords: polarisation, income distribution, inequality

- JEL Classification: D63

- Correspondence to: F. A. Cowell, STICERD, LSE, Houghton St, London WC2A 2AE. (f.cowell@lse.ac.uk) 


\section{Introduction}

The topic of income polarisation has come to play a key role in the analysis of the evolution of income distribution, of the consequences of economic growth and of social conflict. In order to make use of this concept in economic models the idea of polarisation has to be transformed into a precise criterion that can be applied to income distributions: typically some kind of polarisation measure is used. The approach to the measurement of polarisation is usually based on a specific axiom system such as those introduced by Esteban and Ray (1994) and others. However, although the recent work on polarisation is persuasive, it is not clear that the particular axiomatic structures that have been suggested capture the meaning of polarisation as it is commonly understood by social commentators and lay people. Indeed, in popular discussion the terms "polarisation" and "inequality" are not usually clearly distinguished. ${ }^{1}$

The purpose of this paper is to address this issue by investigating the way distributional comparisons are actually perceived. In doing so we focus on ordinal issues concerning the measurement of polarisation rather than on specific polarisation measures. The paper is organised as follows. Section 2 examines the meaning that has been given to the concept of polarisation in the recent literature. Section 3 explains the approach we have adopted in eliciting people's views and perceptions of polarisation. Section 4 describes the samples used for our study and Sections 5 to 7 examine the results. Section 8 concludes.

\section{The meaning of polarisation}

In other social-science disciplines polarisation is often considered as a process. In politics, it is a process by which the public opinion divides and goes to the extremes. In communications and psychology the process involves a social or political group dividing into two opposing sub-groups with fewer and fewer members of the group remaining neutral or holding an intermediate position. In the case of income polarisation the accepted meaning is less clear cut, but no less interesting.

The concept of polarisation assumes the existence of poles - normally two. It also assumes the agglomeration of members of the community at more than

\footnotetext{
${ }^{1}$ For example a summary by the $\mathrm{BBC}$ of a recent empirical study of the UK income distribution noted "[...] during the 1980s and 1990s inequality had increased, as a 'polarisation' in British society had occurred." See http://news.bbc.co.uk/2/hi/business/6901147.stm
} 
one pole. In the context of income polarisation the poles are simply income levels. Beyond this one needs to provide some kind of structure that gives meaning to the concept as well as the basis for deriving computable indices. This is the role played by the introduction of an explicit axiomatisation as in the classic study by Esteban and Ray (1994) and the recent paper by Chakravarty and Majumdar (2001). ${ }^{2}$ The typical axiom systems and the meaning of individual axioms are discussed below in section 2.1.

Some of the axioms used to pin down the meaning of polarisation comparisons have a similar flavour to those used in the literature on income inequality, social welfare and poverty and we will find that it is appropriate to analyse these in a manner that draws on the empirical literature concerning attitudes to distributional comparisons that have been developed in those related fields. However not too much should be made of this similarity because polarisation is a distinct concept and requires a distinct axiomatisation.

In particular it is important to recognise the essential differences between inequality and polarisation. Indeed it is arguable that one of the driving forces that led to the formulation of an explicit concept of income polarisation in the 1990s was the recognition that inequality, as conventionally defined, misses out on some key aspects of the evolution of income distributions over time that should be of concern to policy analysts and social commentators (Wolfson 1994, 1997). The key to the conventional approach to inequality is the transfer principle but it is not clear that respect for this principle is always appropriate for distributional comparisons in terms of polarisation.

\subsection{Axioms}

In the literature there are a number of alternative axiom systems for polarisation; we concentrate here on those in Esteban and Ray (1994) and Chakravarty and Majumdar (2001) and present them in a uniform notation. An income distribution is given by a pair $(\mathbf{p}, \mathbf{x})$ where $\mathbf{p} \in \mathbb{R}_{+}^{n}, \mathbf{x} \in \mathbb{R}_{++}^{n}$ and the set of all such pairs is denoted by $\mathcal{D}$; in other words we characterise a distribution as a vector of non-negative population masses $\left(p_{1}, p_{2}, \ldots, p_{n}\right)$ located on the "rungs" of an income ladder $\left(x_{1}, x_{2}, \ldots, x_{n}\right)$, where each rung is a strictly positive number. A polarisation index is a function $P: \mathcal{D} \rightarrow \mathbb{R}_{+}$.

For any $(\mathbf{p}, \mathbf{x}) \in \mathcal{D}$ let the median be given by

$$
\hat{x}=\hat{x}(\mathbf{p}, \mathbf{x})=\max \left\{x_{j}: \sum_{i=1}^{j} p_{i} \leq \frac{1}{2} \sum_{i=1}^{n} p_{i}\right\} .
$$

\footnotetext{
${ }^{2}$ See also the contributions by Wang and Tsui (2000), Rodriguez and Salas (2003), Bossert and Schworm (2006) and Esteban et al. (2007).
} 
The median can be used to divide the population into two groups ("poorer", "richer") that provide intuition for some of the axioms. In the following description of the axioms the labels "ERx" means "Axiom $\mathrm{x}$ in Esteban and Ray (1994)"; the others are those used by Chakravarty and Majumdar (2001) or are in common use elsewhere.

The axioms in Esteban and Ray (1994) are all stated in terms of an elementary "three-rung" income distribution. Accordingly in Axioms 1 to 4 we assume that $\mathbf{p}$ and $\mathbf{x}$ have dimension 3 , that $\mathbf{p}>\mathbf{0}$ and that $x_{1} \leq x_{2} \leq x_{3}{ }^{3}$

Axiom 1 (ER1) Let $p_{1}>p_{2}=p_{3}$ and $x_{1}<x_{2}<x_{3}$. Then, for $p_{2} / p_{1}$ sufficiently small and $x_{3} / x_{2}$ sufficiently small:

$$
P\left(\left(p_{1}, 2 p_{2}\right),\left(x_{1}, \sqrt{x_{2} x_{3}}\right)\right)>P(\mathbf{p}, \mathbf{x})
$$

Axiom 2 (ER2) Let $p_{1}>p_{3}$ and $x_{2} / x_{1}>x_{3} / x_{2}>1$. Then there exists a small positive $\delta$ such that

$$
P\left(\mathbf{p},\left(x_{1}, x_{2}+\delta, x_{3}\right)\right)>P(\mathbf{p}, \mathbf{x})
$$

Axiom 3 (ER3) Let $x_{3} / x_{2}=x_{2} / x_{1}>1$. Then for all $\delta \in\left(0, \frac{1}{2} p_{2}\right)$ :

$$
P\left(\left(p_{1}+\delta, p_{2}-2 \delta, p_{3}+\delta\right), \mathbf{x}\right)>P(\mathbf{p}, \mathbf{x})
$$

Axiom 4 (ER4) Let $p_{2}>p_{3}$ and $x_{3} / x_{2}=x_{2} / x_{1}>1$. Then, for $p_{1}$ and $p_{2}-p_{3}$ sufficiently small and for $\delta \in\left(0, p_{1}\right)$ :

$$
P\left(\left(p_{1}-\delta, p_{2}, p_{3}+\delta\right), \mathbf{x}\right) \geq P(\mathbf{p}, \mathbf{x})
$$

Other axioms can be conveniently stated for arbitrary members of the set of income distributions $\mathcal{D}$.

Axiom 5 (Increased spread) Consider $\left(\mathbf{p}, \mathbf{x}^{\prime}\right),(\mathbf{p}, \mathbf{x}) \in \mathcal{D}$ such that $x_{h}^{\prime}=$ $x_{h}, h \neq i$ and let $\delta>0$. If either (a) $x_{i}<\hat{x}$ and $x_{i}^{\prime}=x_{i}-\delta$ or (b) $x_{i}>\hat{x}$ and $x_{i}^{\prime}=x_{i}+\delta$ then $P\left(\mathbf{p}, \mathbf{x}^{\prime}\right)>P(\mathbf{p}, \mathbf{x})$.

Axiom 6 (Increased bipolarity) Consider $\left(\mathbf{p}, \mathbf{x}^{\prime}\right),(\mathbf{p}, \mathbf{x}) \in \mathcal{D}$ such that $x_{i}^{\prime}=x_{i}+\delta, x_{j}^{\prime}=x_{j}-\delta, x_{h}^{\prime}=x_{h}, h \neq i, j$ where $x_{i}+2 \delta \leq x_{j}$ and $\delta>0$. If either (a) $x_{i}<x_{j}<\hat{x}$ or (b) $x_{j}>x_{i}>\hat{x}$ then $P\left(\mathbf{p}, \mathbf{x}^{\prime}\right)>P(\mathbf{p}, \mathbf{x})$.

\footnotetext{
${ }^{3}$ Esteban and Ray (1994) work with log incomes, which explains the use of the geometric mean (instead of the arithmetic mean) in Axiom 1. in addition one could follow Esteban and Ray's practice and normalise $x_{1} \equiv 1$, but this is not essential.
} 
Axiom 7 (Principle of population ) For any $(\mathbf{p}, \mathbf{x}) \in \mathcal{D}$ and any positive integer $m, P(m \mathbf{p}, \mathbf{x})=P(\mathbf{p}, \mathbf{x})$

Axiom 8 (Scale independence) For any $(\mathbf{p}, \mathbf{x}) \in \mathcal{D}$ and any $\lambda>0$, $P(\mathbf{p}, \lambda \mathbf{x})=P(\mathbf{p}, \mathbf{x})$

Axiom 9 (Translation independence) For any $(\mathbf{p}, \mathbf{x}) \in \mathcal{D}$ and any $\delta \in$ $\mathbb{R}, P\left(\mathbf{p}, \mathbf{x}+\delta \mathbf{1}^{n}\right)=P(\mathbf{p}, \mathbf{x})$

The interpretation of the Esteban and Ray (1994) axioms is as follows: polarisation is increased by pooling two small population masses on the upper income rungs ${ }^{4}$ (Axiom 1), by increasing intermediate income in a special three-income society (Axiom 2) or by moving population mass from the middle outwards (Axiom 3); migration from a very small population mass at a low income to a moderately-sized high income (Axiom 4) will not reduce polarisation. Alternatively (from Chakravarty and Majumdar 2001) polarisation must increase if you decrease the income of someone in the poorer group or if you increase the income of someone in the richer group (Axiom 5 ), or if you bunch incomes closer together within the poorer or the richer group (Axiom 6). Finally some general points about structure: Polarisation remains unchanged if you replicate the population (Axiom 7); if we accept Axiom 8 then merely rescaling all incomes together leaves polarisation unchanged; but if we accept Axiom 9 then adding (or subtracting) the same absolute amount to all incomes leaves polarisation unchanged. ${ }^{5}$

It is interesting to compare these with axioms that are commonly invoked in other topics within the field of distributional analysis. Axiom 7 and Axioms 8 or 9 of course appear in many contexts including poverty and inequality. Axiom 5 part (a) corresponds to the monotonicity axiom in poverty analysis if the poverty line is below median income. The income transformation implied in Axiom 3 is consistent with an inequality change that respects the transfer principle (Dalton 1920): i.e. in this special case polarisation and inequality move in the same direction. But it is a very special case. Contrast this with the income transfers implied in Axiom 6 where the implied transfer is entirely on one side of the median and it is clear that polarisation must go up exactly where inequality must go down according to the transfer principle.

Finally note that some axioms appear to be closely related: for example Axiom 6 appears to be a more general form of Axiom 1 and Axiom 2 is

\footnotetext{
${ }^{4}$ Replacing $x_{2}, x_{3}$ by their geometric mean

${ }^{5}$ Clearly it may also make sense to consider alternatively an "intermediate" position between scale-independence and translation independence. This is analogous to intermediate inequality measures (Bossert and Pfingsten 1990); other forms of systematic incomedependence may also be relevant (Amiel and Cowell 1999a).
} 
similar to part (b) of Axiom 5. We shall have more to say about these apparent similarities below and a formal discussion is in Appendix A.

\subsection{Measures}

Corresponding to specific subsets of the axioms introduced in section 2.1 we find specific classes of polarisation measure. For example, by focusing on the partition induced by the median (Axioms 5 to 7 ) one is led naturally to the following class of measures

$$
P^{I}(\mathbf{p}, \mathbf{x}):=\phi\left(I\left(\mathbf{p}^{-}, \mathbf{x}\right), I\left(\mathbf{p}^{+}, \mathbf{x}\right), \hat{x}, \mu^{-}, \mu^{+}\right)
$$

where $\phi$ is strictly decreasing in each of its first two arguments, $I$ is an inequality index satisfying the transfer principle, $\hat{x}:=\hat{x}(\mathbf{p}, \mathbf{x})$ and

$$
\begin{gathered}
p_{i}^{-}:=\left\{\begin{array}{cc}
p_{i} & \text { if } x_{i}<\hat{x} \\
0 & \text { otherwise }
\end{array},\right. \\
p_{i}^{+}:=\left\{\begin{array}{cc}
p_{i} & \text { if } x_{i}>\hat{x} \\
0 & \text { otherwise }
\end{array},\right. \\
\mu^{-}:=\frac{\sum_{i=1}^{n} p_{i}^{-} x_{i}}{\sum_{i=1}^{n} p_{i}^{-}} \\
\mu^{+}:=\frac{\sum_{i=1}^{n} p_{i}^{+} x_{i}}{\sum_{i=1}^{n} p_{i}^{+}} .
\end{gathered}
$$

This is the approach of Chakravarty and Majumdar (2001) and Wang and Tsui (2000). ${ }^{6}$ By contrast, by invoking Axioms 1-3 and assuming a quasiadditive structure for the polarisation index, Esteban and Ray (1994) derived the index

$$
P^{\alpha}(\mathbf{p}, \mathbf{x}):=\sum_{i=1}^{n} \sum_{j=1}^{n} p_{i}^{1+\alpha} p_{j}\left|\log \left(\frac{x_{j}}{x_{i}}\right)\right|,
$$

where $\alpha$ is a positive parameter. ${ }^{7}$

Of course this still leaves the exact characterisation of the polarisation measure open-ended. For the measure $P^{I}$ one still has to specify the index $I$

\footnotetext{
${ }^{6}$ In addition to Axioms 5 to 7 Chakravarty and Majumdar (2001) invoke three other properties, symmetry, normalisation and continuity, to derive their measure (see their Proposition 1).

${ }^{7}$ See Esteban and Ray (1994) Theorem 1.
} 
- Chakravarty and Majumdar (2001) suggest the Atkinson index, Wang and Tsui (2000) suggest the Gini. For the measure $P^{\alpha}$ one still has to specify the parameter $\alpha$ - Esteban and Ray (1994) provide an argument that it must be less than 1.6 (implicit in the proof of their Theorem 1) and, if Axiom 4 is invoked, it must be greater than $1 .^{8}$ Clearly, whether $P^{I}$ satisfies Axiom 8 or Axiom 9 or some other general principle of income levels (see footnote 5 above) will depend in part on the properties of the $I$ that has been specified; clearly also $P^{\alpha}$ satisfies Axiom 8 but not Axiom 9 .

\section{The Approach}

\subsection{Questionnaires}

We used a standard technique to investigate whether this formulation of polarisation is "appropriate" in that it corresponds with individuals' views. The method follows that of earlier work on inequality, poverty and social welfare (Amiel and Cowell 1992, 1999b).

The basic idea is to set up a number of income-distribution comparisons and to invite respondents to state which of the two distributions represents greater polarisation. So the approach is purely ordinal and, given an appropriate collection of income-distribution pairs, it is possible to get some insight on whether the structures imposed by the axiomatisation are consistent with the principles that underlie people's perceptions of polarisation.

Of course, as in the inequality and other studies, we also need to check on whether respondents are influenced by the way questions are presented. In the present case this takes two forms:

- Within a questionnaire we pose questions both in the form of specific numerical problems and, later, also in terms of principles expressed verbally.

- We used a variety of formats for the questionnaire concurrently. Since the initial contributions to the polarisation literature appealed strongly to individual intuition in establishing the concept it is clearly important to use alternative representations in order to appeal to our respondents' intuition. Some respondents completed the questionnaire on-line in an interactive environment, VLAB, established at the Distributional Research Programme, of STICERD, LSE. Others completed the questionnaire in the corresponding hardcopy form. Both versions

\footnotetext{
${ }^{8}$ See Esteban and Ray (1994) Theorem 3.
} 
were prepared in three forms of questionnaire that presented the numerical representation in different ways, as follows.

1. With hints. The two distributions are presented as simple vectors, written out in full. Where components differ between the two income vectors these are highlighted in bold to emphasise to the respondent what particular implied change in the distribution he or she ought to be looking at.

2. No hints. As above, but without putting particular vector components in bold.

3. Pictures. We use a simple graphic based on the usage in Amiel and Cowell $(1999 b)$ to represent the two distributions on an income line.

A number of variants of the questionnaires were used in order to examine specific hypotheses - how these questionnaires differed from one another is explained in section 6 . The questionnaires themselves are available at http://darp.lse.ac.uk/polarisation/ and the master version used for reference in this paper is reprinted in Appendix C. It is important to note that this master version was not the one used for the bulk of our respondents: the versions used in the initial phase with our main sample (reported in section 5) were slightly shorter, omitting questions 11, 12 and 22.

\subsection{Axioms and questions}

Many of the questions to be addressed concern the extent to which respondents' views correspond to individual axioms or principles employed in the polarisation literature. The relationship between the question used in our study, the Axioms set out in section 2.1 and other properties highlighted in Esteban and Ray (1994) are given in Table 1. If a substantial proportion of respondents answer questions in a way that is systematically different from the entry on the right-hand side of the table, there is prima facie reason to call into question the corresponding axiom or principle.

Are there specific principles in Table 1 that should be of special interest as being central to the idea of polarisation? Perhaps the two most important issues are:

- Axioms 1 and 6 . Axiom 6 "explicitly demonstrates that polarisation and inequality are two different concepts" (Chakravarty and Majumdar 2001, p.6); furthermore it appears to capture a similar idea to Axiom 


\begin{tabular}{ll}
\hline \hline Axiom & Answers consistent with axiom \\
\hline Axiom 1 & $11 \mathrm{~B}, 12 \mathrm{~B}, 22 \mathrm{~B}$ \\
Axiom 2 & $6 \mathrm{~B}, 18 \mathrm{~A}$ \\
Axiom 3 & $7 \mathrm{~B}, 19 \mathrm{~A}$ \\
Axiom 4 & $8 \mathrm{~B}, 20 \mathrm{~A}$ \\
& \\
Axiom 5 & $1 \mathrm{~A}, 9 \mathrm{~A}, 7 \mathrm{~B}, 10 \mathrm{~A}, 13 \mathrm{aC}, 13 \mathrm{bB}, 21 \mathrm{~A}$ \\
Axiom 6 & $2 \mathrm{~A}, 14 \mathrm{~B}$ \\
Axiom 7 & $3 \mathrm{AB}, 15 \mathrm{C}$ \\
Axiom 8 & $4 \mathrm{AB}, 5 \mathrm{~A}, 16 \mathrm{~A}, 17 \mathrm{~A}$ \\
Axiom 9 & $5 \mathrm{AB}, 4 \mathrm{~B}, 17 \mathrm{~B}, 16 \mathrm{~B}$ \\
& \\
Relevance of isolated ind. (Esteban and Ray 1994) & $1 \mathrm{AB}, 13 \mathrm{aB}, 13 \mathrm{bC}$ \\
Non-monotonicity (Esteban and Ray 1994) & $1 \mathrm{~B}, 9 \mathrm{~B}, 10 \mathrm{~A}, 21 \mathrm{D}$ \\
\hline
\end{tabular}

Table 1: Axioms and questions

1 as well as being related to Esteban and Ray's discussion of the behaviour of $P^{\alpha}$ under progressive transfers (p.844). An important issue is whether Axiom 6 can be taken as just a more general form of Axiom 1: this question is examined formally in Appendix A and its empirical implications in section 6.2.

- The non-monotonic behaviour attributed to polarisation (Esteban and Ray 1994). Non-monotonicity is potentially important for at least two reasons. First, it clashes with Axiom 5 (described by Chakravarty and Majumdar (2001) as a monotonicity property). Now, if Esteban and Ray's measure does not satisfy this property it could be an indication as to whether Esteban and Ray's measure is preferred to the others, say Chakravarty and Majumdar's. Second, it can provide some insight as to whether lay people give more importance to "intergroup differences" or to "within group homogeneity," which in turn drive Esteban and Ray's model (i.e. alienation and identification).

In discussing the "intermediate behaviour" of their measure Esteban and Ray (1994) show that if initial polarisation is relatively large then as population moves away from two central masses, to the extremes, polarisation as measured by $P^{\alpha}$ first decreases and then increases. ${ }^{9}$ Such a transition is captured by question 9 where initial polarisation is large as in Esteban and Ray

\footnotetext{
${ }^{9}$ See their Figures 5 and 6 (Esteban and Ray 1994 p. 848) : the interesting transition in Figure 5 (our Figure 1) is from panels (a) to (b).
} 
(1994). Therefore, we can check whether respondents are giving coherent or consistent answers by checking whether their answers comply with the three axioms used in Theorem 1 of Esteban and Ray (1994) while also answering that polarisation should not be monotonic in situations such as that depicted in Figure 1. In terms of our questions this implies the following sequence:

$\begin{array}{lll}\text { Axiom 1 } & \rightarrow & 11 \mathrm{~B}, 12 \mathrm{~B}(22 \mathrm{~B}) \\ \text { Axiom } 2 & \rightarrow & 6 \mathrm{~B}(18 \mathrm{~A}) \\ \text { Axiom 3 } & \rightarrow & 7 \mathrm{~B}(19 \mathrm{~A}) \\ \text { Nonmonotonicity in Figure 1 } & \rightarrow & 1 \mathrm{~B}, 9 \mathrm{~B}, 10 \mathrm{~A}(21 \mathrm{D})\end{array}$
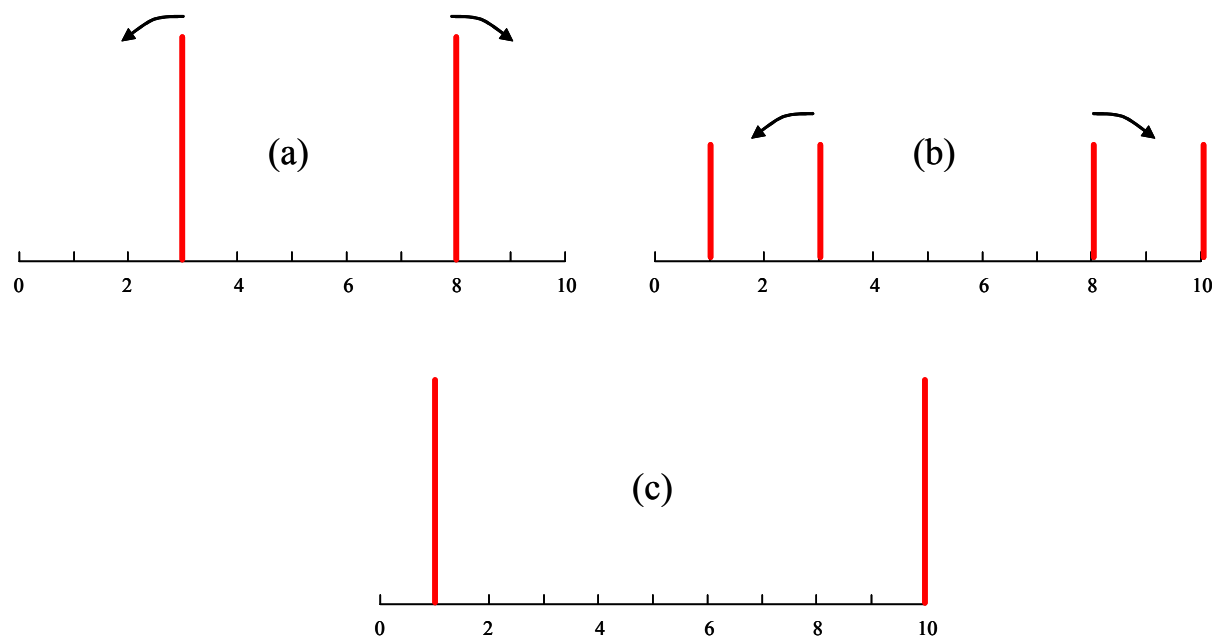

Figure 1: Nonmonotonicity in polarisation

\subsection{Relations among axioms}

We can do more than examine individual principles using the questionnaireexperimental approach. The proportion of the sample who simultaneously give the responses listed in rows $1-3$ of Table 1 can be taken as an indication of the extent to which individuals intuit polarisation in a manner consistent with Esteban and Ray (1994)'s polarisation index, $P^{\alpha}$ given in equation (2).

Likewise the proportion of the sample who, in addition to the above, also give the responses of row 4 can be taken as an indication of the extent to which polarisation is perceived in the narrower form of $P^{\alpha}$ with $\alpha \geq 1 .^{10}$

\footnotetext{
${ }^{10}$ This means that sensitivity parameter is sufficiently large that $P^{\alpha}$ is not close to an inequality index (Gini defined on log incomes) - see Esteban and Ray (1994) Theorem 3.
} 
In addition the proportion of the sample who respond in line with rows $5,6,7$ of Table 1 can be taken as an indication of the extent of "support" for the $P^{I}$ index (1) suggested by Chakravarty and Majumdar (2001).

\subsection{Additional checks}

We also check on 'symmetry' regarding the constituent parts (a) and (b) Axiom 5, using questions 13a and 13b. It may also be thought that the arguments given in the options of the verbal questions could drive individuals towards the 'right' answer. To check that, we also ran some questionnaires with bare verbal answers, i.e. increase, decrease, remains the same.

\section{The Samples}

The questionnaire-experiments reported here consisted of a main study and two follow-up investigations.

\subsection{Main study}

Our main sample consisted of 1521 students from eleven universities spread amongst six countries, which we use for the main study, and two smaller samples that we use to test several hypothesis or conjectures which arose from the analysis of the main sample. The three samples are shown in Table 2. Average age in the main sample is 22 , and the gender composition is fairly equally balanced. Most of them are economics and business students but we also sampled students from other social sciences, and to a lesser extent from other disciplines. Notice that the distribution of the type of questionnaire is also balanced, with the pictorial version being slightly more used than the other two. Average political views lay in the mid-point of the support and, on average, respondents expect to be financially better-off in ten years' time than were their families ten years ago.

\subsection{Follow-up studies}

As outlined above and explained in more detail in Section 6, to address two specific issues that arose from the analysis of the main sample, we implemented two follow-up studies with smaller samples. The first follow-up study uses two subsamples of 131 and 128 individuals who responded to two 


\begin{tabular}{|c|c|c|c|c|c|c|c|c|}
\hline \multirow[b]{3}{*}{ Variable } & \multirow{2}{*}{\multicolumn{2}{|c|}{$\begin{array}{l}\text { Main } \\
\text { study }\end{array}$}} & \multicolumn{4}{|c|}{ Follow-up study 1} & \multirow{2}{*}{\multicolumn{2}{|c|}{$\begin{array}{l}\text { Follow-up } \\
\text { study } 2\end{array}$}} \\
\hline & & & \multicolumn{2}{|c|}{ Polarisation } & \multicolumn{2}{|c|}{ Inequality } & & \\
\hline & $N$ & val $^{*}$ & $N$ & $\mathrm{val}^{*}$ & $N$ & $\mathrm{val}^{*}$ & $N$ & $\mathrm{val}^{*}$ \\
\hline Age & 1445 & 22.11 & 128 & 20.45 & 118 & 19.94 & 183 & 22.45 \\
\hline Political views & 1392 & 3.61 & 123 & 3.06 & 108 & 3.17 & 178 & 2.86 \\
\hline Family income in 1995 & 1425 & 4.09 & 125 & 3.89 & 112 & 4.03 & 181 & 4.02 \\
\hline Income prospects in 2015 & 1422 & 4.68 & 126 & 4.90 & 111 & 5.17 & 181 & 4.65 \\
\hline Gender & 1449 & & 128 & & 116 & & 183 & \\
\hline Female & 757 & 52.24 & 79 & 61.72 & 68 & 58.62 & 99 & 54.1 \\
\hline Male & 692 & 47.76 & 49 & 38.28 & 48 & 41.38 & 84 & 45.9 \\
\hline Employed before university & 1403 & & 127 & & 117 & & 180 & \\
\hline No & 733 & 52.25 & 37 & 29.13 & 42 & 35.90 & 52 & 28.9 \\
\hline Yes & 670 & 47.75 & 90 & 70.87 & 75 & 64.10 & 128 & 71.1 \\
\hline Subject of study & 1478 & & 131 & & 128 & & 191 & \\
\hline Economics & 632 & 42.76 & 51 & 38.93 & 48 & 37.5 & 46 & 25.6 \\
\hline Business & 591 & 39.99 & 41 & 31.30 & 40 & 31.25 & 49 & 24.1 \\
\hline Social Sciences & 175 & 11.84 & 39 & 29.77 & 40 & 31.25 & 96 & 50.3 \\
\hline Other & 80 & 5.41 & 0 & 0.00 & 0 & 0.00 & 0 & 0.00 \\
\hline \multicolumn{9}{|l|}{ Language of questionnaire } \\
\hline Catalan & 550 & 36.16 & 131 & 100.00 & 128 & 100.00 & 191 & 100.00 \\
\hline English & 363 & 23.87 & 0 & 0.00 & 0 & 0.00 & 0 & 0.00 \\
\hline Spanish & 608 & 39.97 & 0 & 0.00 & 0 & 0.00 & 0 & 0.00 \\
\hline \multicolumn{9}{|l|}{ University** $^{* *}$} \\
\hline LSE & 83 & 5.46 & 0 & 0.00 & 0 & 0.00 & 0 & 0.00 \\
\hline UAB & 343 & 23 & 131 & 100.00 & 128 & 100.00 & 191 & 100.00 \\
\hline UB & 145 & 9.53 & 0 & 0.00 & 0 & 0.00 & 0 & 0.00 \\
\hline UEC & 87 & 5.72 & 0 & 0.00 & 0 & 0.00 & 0 & 0.00 \\
\hline UHOB & 60 & 3.94 & 0 & 0.00 & 0 & 0.00 & 0 & 0.00 \\
\hline UI & 64 & 4.21 & 0 & 0.00 & 0 & 0.00 & 0 & 0.00 \\
\hline UMON & 69 & 4.54 & 0 & 0.00 & 0 & 0.00 & 0 & 0.00 \\
\hline UOC & 94 & 6.18 & 0 & 0.00 & 0 & 0.00 & 0 & 0.00 \\
\hline UR & 185 & 12.16 & 0 & 0.00 & 0 & 0.00 & 0 & 0.00 \\
\hline URJC1 & 210 & 13.81 & 0 & 0.00 & 0 & 0.00 & 0 & 0.00 \\
\hline UV & 181 & 11.9 & 0 & 0.00 & 0 & 0.00 & 0 & 0.00 \\
\hline \multicolumn{9}{|l|}{ Type of Questionnaire } \\
\hline Hints & 426 & 28.01 & 46 & 35.11 & 44 & 34.38 & 0 & 0.00 \\
\hline No Hints & 454 & 29.85 & 45 & 34.35 & 42 & 32.81 & 0 & 0.00 \\
\hline Pictures & 641 & 42.14 & 40 & 30.53 & 42 & 32.81 & 191 & 100.00 \\
\hline \multicolumn{9}{|c|}{ * "Val" gives mean of relevant variable or percentage with specified characteristic } \\
\hline $\begin{array}{l}\text { Hobart University, University of Istanbul, } \\
\text { República, Universidad Rey Juan Carlo }\end{array}$ & $\begin{array}{l}\text { onash } \\
\text { Univer }\end{array}$ & Inersty & & de C & & dad de la & & \\
\hline
\end{tabular}

Table 2: Descriptive Statistics of our Sample 
parallel questionnaires, on inequality and polarisation, with the aim of .finding out whether respondents answer to polarisation questions as though they are being presented with inequality questions - the differences between these two questionnaires and the relationship to the one used in the main study are explained in Section 6.1. The second follow-up study samples 191 individuals to check whether the Increased Bipolarity property is an adequate proxy for the ER1 axiom. The strategy of running two parallel questionnaires is also used in this follow-up study, obtaining rather balanced subsamples.

The composition of the follow-up samples is very similar to the main sample; however, they come from only one university (UAB) and the second follow-up study uses only the picture-type questionnaire.

\section{Results: a first look}

Let us examine the extent to which individuals' perceptions of polarisation accord to the axioms or features commonly used in the economics literature and outlined above. We begin by reporting on the initial phase of our study that used a shorter version of the questionnaire ${ }^{11}$ allowing the Increased Bipolarity principle (Axiom 6) to proxy for the ER1 (Axiom 1). In the light of the results from this initial phase two follow-up studies were carried out, discussed in section 6. In order to follow the ordering of questions in the questionnaire we shall report first on Axioms 5 to 9, and then proceed with the axioms used in Esteban and Ray (1994).

\subsection{Axiom 5: Increased Spread}

Question 1 (Q1) shows that there seems to be an overwhelming majority that supports this property $(60 \%)$ - see Table 3 . The corresponding verbal questions $13 \mathrm{a}$ and $13 \mathrm{~b}$ yield similar results (69\% and $71 \%$, respectively), which is a clear sign of symmetry in the evaluation of (similar) changes when occurring at different ends (or halves) of the distribution. That is, individuals do not seem to give more importance to a given "gap" at the lower rather than the upper half of the distribution.

The overwhelming evidence in favour of Axiom 5 remains when other numerical questions $(7,9,10)$ are used. Notwithstanding this, one should interpret the evidence from these questions with caution. These three questions

\footnotetext{
${ }^{11}$ This can be generated by omitting questions 11,12 and 22 from the master version in Appendix $\mathrm{C}$ and renumbering
} 


\begin{tabular}{lrrrr}
\hline \hline & Question 1 & Question 13a & Question 13b & Question 10 \\
\cline { 2 - 5 } Increases & 59.5 & 68.8 & 70.5 & 75.8 \\
Same & 6.1 & 12.0 & 11.0 & 8.9 \\
Decreases & 34.4 & 13.2 & 12.2 & 15.3 \\
Depends & 6.0 & 6.3 & \\
$\mathrm{~N}$ & 1507 & 1497 & 1486 & 1506 \\
\hline Note: 'Orthodox' answers in italics \\
\hline
\end{tabular}

Table 3: Increased Spread

involve somewhat larger changes than question 1, and thus other properties may be driving the answer. Take question 10 . On the one hand, the transition from distribution B to A should increase polarisation, according to Axiom 5 - which is the answer we mostly get. On the other hand, however, one should bear in mind that Q10 is moving the two poles further apart without creating any dispersion around any of them, i.e. in Esteban and Ray (1994)'s terms, it increases alienation without introducing any loss in identification. Question 1, instead, proposes a change in the income of only one individual, thus implying a loss in identification and no increase in alienation.

\subsection{Axiom 6: Increased Bipolarity}

This property does not seem to enjoy much support, in whatever form the issue is posed. This result is remarkable - perhaps unfortunate - because the property provides a clear distinction between polarisation and inequality. As shown in Table 4, only 30\% of the sample provides an answer to Q2 that is consistent with the axiom. This percentage falls to $20 \%$ in the verbal question 14. Perhaps our representation of the property is too weak to transmit the essence of the axiom in that respondents might consider that such small changes do not make any difference; $16 \%$ and $48 \%$ view the changes proposed in Q2 and Q14, respectively, as having no effect on polarisation. Interestingly, the option enjoying the largest support is that an equalizing transfer decreases polarisation. Our interpretation of this result is different for the two questions. In the numerical question 2 this may be influenced by the lowest income in distribution $\mathrm{B}$ being smaller than the corresponding one in distribution A (together with the fact that the transfer is small in absolute terms). Such a result in Q2 could also arise because the equalizing transfer implies a loss in identification (the pole at 10 loses one fourth of its mass, and the movement does not generate another pole but creates a somewhat blurred picture at the bottom end of the distribution). The rather large support for a decrease in the verbal question 14, however, might be 


\begin{tabular}{lrr}
\hline \hline & Question 2 & Question 14 \\
\cline { 2 - 3 } Increases & 30.1 & 19.7 \\
Same & 16.2 & 47.8 \\
Decreases & 53.7 & 32.5 \\
$\mathrm{~N}$ & 1497 & 1441 \\
\hline Note: 'Orthodox' answers in italics \\
\hline
\end{tabular}

Table 4: Increased Bipolarisation

due to a different reason. Our conjecture is that the suggested explanations in the first two options may trick the respondent. Put crudely, option a) suggests that polarisation falls because a certain gap increases, while option b) suggests that it has actually increased because the distance between two individuals becomes smaller. Now, if individuals let these two distances drive their answer, a likely outcome is concluding that polarisation has decreased. In order to test such conjecture, we have used a version of the questionnaire with bare verbal questions - that is, without explanations - and have used regression analysis to test the (statistical) significance of the variable that identifies this 'experiment' - i.e. that identify the questionnaires with bare verbal answers. The answers given by this 'bare-verbal-questions' sample support this conjecture: now individuals do not favour the 'decrease' option as much (being now the 'decrease' answer as popular as the 'increase' option) and tend to think instead that an equalising transfer leaves polarisation unchanged - see Table 24 in Appendix B.

As outlined above, Increased Bipolarity is about equalizing transfers, and to the eyes of many such transfers decrease inequality (Amiel and Cowell 1992, 1999b). Thus, another possibility is that respondents be heavily influenced by the notion of inequality when assessing the equalizing transfer which takes place from distribution $\mathrm{B}$ to $\mathrm{A}$ in Q2 or when deciding about the effect of the rich-to-poor income transfer of Q14. We study this issue in section 6.1 .

Finally, from the answers to this question one could surmise that the level of income of the poorest individual may have a large impact on a person's polarisation assessment. This conjecture also arises when trying to understand the answers to some other questions. 


\begin{tabular}{lrr}
\hline \hline & Question 3 & Question 15 \\
\cline { 2 - 3 } Increases & 29.3 & 12.8 \\
Same & 57.1 & 82.9 \\
Decreases & 13.6 & 4.3 \\
$\mathrm{~N}$ & 1496 & 1468 \\
\hline Note: 'Orthodox' answers in italics \\
\hline
\end{tabular}

Table 5: Population Principle

\subsection{Axiom 7: Population Principle}

Table 5 shows that a large majority of the sample gives responses in line with the population principle $-57 \%$ and $83 \%$ in the numerical and the verbal questions, respectively. Actually, the verbal question is more convincing or persuasive than the numerical one (69\% of those who did not answer in line with the principle in the numerical question did so in the verbal one). Given the above, it is no surprise that nearly everyone who answered in line with the population principle in the numerical question 3 also answered in agreement with the principle in Q15 (only 7\% did not).

\subsection{Scale or Translation Invariance?}

Translation invariance looks like winning the contest here, though scale invariance does not enjoy little support, especially in the verbal question - see Table 6 . In both cases, the verbal questions seem more persuasive than the numerical ones. One could be suspicious of the short argument provided in the different options as driving individuals to the answers that are consistent with the axioms. However, the analysis of our "bare-verbal-questions" sample reveals it to be an unfounded suspicion. For instance, in the case of scale invariance (Q14), the brief explanations seem to have the opposite effect, so that when explanations are dropped, increases (to 69\%) the percentage of respondents who agree with the axiom - see Table 26 in Appendix B.

As far as the consistency between numerical and verbal questions is concerned, both pairs of questions provide larger support for translation invariance than for scale invariance. The cross-tab of questions 4 and 16 presented in Table 7 shows that while only $21 \%$ consistently agree with scale invariance, those answering in line with translation invariance represent $24 \%$ of 


\begin{tabular}{lrrrr}
\hline \hline & Question 4 & Question 5 & Question 16 & Question 17 \\
\cline { 2 - 5 } Increases & $\mathbf{6 1 . 5}$ & 18.0 & $\mathbf{3 0 . 3}$ & 6.7 \\
Same & 28.2 & $\mathbf{5 0 . 2}$ & 53.9 & $\mathbf{6 4 . 9}$ \\
Decreases & 10.3 & 31.8 & 10.8 & 20.7 \\
Depends & & & 5.0 & 7.6 \\
$\mathrm{~N}$ & 1507 & 1497 & 1468 & 1466 \\
\hline
\end{tabular}

Note: Answers consistent with scale invariance in italics; answers consistent with translation invariance in bold

Table 6: Scale or Translation Invariance?

\begin{tabular}{lrrrrr}
\hline \hline & \multicolumn{5}{c}{ Question 16 } \\
\cline { 2 - 6 } Question 4 & Increases & Same & Decreases & Depends & Total \\
\hline Increases & $\mathbf{2 4 . 1}$ & 27.8 & 6.9 & 2.9 & 61.7 \\
Same & 3.9 & 21.4 & 1.7 & 1.1 & 28.1 \\
Decreases & 2.2 & 4.8 & 2.1 & 1.0 & 10.2 \\
Total & 30.2 & 54.0 & 10.7 & 5.0 & 100 \\
\hline
\end{tabular}

Question 17

\begin{tabular}{lrrrrr} 
Question 5 & Increases & Same & Decreases & Depends & Total \\
\hline Increases & 2.8 & 9.6 & 3.5 & 1.9 & 17.8 \\
Same & 1.9 & $\mathbf{4 1 . 2}$ & 4.4 & 2.9 & 50.5 \\
Decreases & 2.0 & 14.3 & 12.6 & 2.8 & 31.7 \\
Total & 6.7 & 65.1 & 20.6 & 7.6 & 100 \\
\hline Note: Answers consistent with scale invariance in italics; \\
answers consistent with translation invariance in bold
\end{tabular}

Table 7: Scale or Translation Invariance? Consistency between Numerical and Verbal Answers

the sample. On the other hand, as much as $41 \%$ do consistently respond in line with translation invariance in questions 5 and 17.

When the answers to both numerical questions (4 and 5) are simultaneously analysed, a smaller percentage of the sample gives consistent responses to either of the postulates. Still, as Table 8 shows, translation invariance continues to gather more support than scale invariance $-32 \%$ and $10 \%$, respectively. As pointed out above, answers to both verbal questions provide large support for both properties. Hence, when the two verbal questions 16 and 17 are cross-checked, fewer individuals than before - with the numerical 


\begin{tabular}{lrrrr}
\hline \hline & \multicolumn{4}{c}{ Question 5 } \\
\cline { 2 - 5 } Question 4 & Increases & Same & Decreases & Total \\
\cline { 2 - 5 } Increases & 11.5 & $\mathbf{3 2 . 0}$ & 17.9 & 61.4 \\
Same & 2.8 & 15.2 & 10.3 & 28.3 \\
Decreases & 3.7 & 3.1 & 3.6 & 10.3 \\
Total & 18.0 & 50.3 & 31.7 & 100 \\
\hline
\end{tabular}

\begin{tabular}{lrrrrr} 
& \multicolumn{5}{c}{ Question 17 } \\
\cline { 2 - 6 } Question 16 & Increases & Same & Decreases & Depends & Total \\
\hline Increases & 2.3 & $\mathbf{1 8 . 2}$ & 7.5 & 2.4 & 30.3 \\
Same & 3.3 & 39.5 & 8.5 & 2.5 & 53.8 \\
Decreases & 0.9 & 5.1 & 3.4 & 1.5 & 10.9 \\
Depends & 0.3 & 2.2 & 1.3 & 1.2 & 5.0 \\
Total & 6.7 & 64.9 & 20.8 & 7.7 & 100 \\
\hline Note: Answers consistent with scale invariance in italics; \\
answers consistent with translation invariance in bold \\
\hline
\end{tabular}

Table 8: Scale or Translation Invariance? Consistency Across Questions

questions - provide consistent support for either of the two axioms (8\% and $18 \%$, respectively). Interestingly, the most popular response that arises from the cross-tab of the two verbal questions (39\%) is in line with the property being tested by each question. Such a pattern is not so important in the numerical questions - though it is the third most populated option, behind the consistent answers to the two properties.

\subsection{Axioms 2 and 3: ER2 and ER3}

Now consider axioms 2 and 3. Both of them receive overwhelming support from our sample respondents. A look at the responses to each question reveals that in both cases more than $65 \%$ of the respondents answer in line with the axiom being tested. Moreover, more than half of the whole sample provides consistent answers to the numerical and verbal questions.

\subsection{Axiom 4: ER4}

Axiom 4 receives somewhat less support - see Table 10. No more than $40 \%$ of the respondents provides a response in line with this axiom in both the 


\begin{tabular}{|c|c|c|c|c|}
\hline \multirow[b]{3}{*}{ Increases } & \multicolumn{2}{|c|}{ Axiom 2} & \multicolumn{2}{|c|}{ Axiom 3} \\
\hline & Question 6 & Question 18 & Question 7 & Question 19 \\
\hline & 71.8 & 65.8 & 76.9 & 67.4 \\
\hline Same & 8.3 & 10.3 & 5.8 & 15.2 \\
\hline Decreases & 19.9 & 15.1 & 17.3 & 8.6 \\
\hline Depends & & 8.9 & & 8.7 \\
\hline $\mathrm{N}$ & 1506 & 1460 & 1506 & 1458 \\
\hline
\end{tabular}

Table 9: Axioms 2 and 3

\begin{tabular}{lrr}
\hline \hline & Question 8 & Question 20 \\
\cline { 2 - 3 } Increases & 38.9 & 27.4 \\
Same & 3.1 & 9.6 \\
Decreases & 58.1 & 63.0 \\
$\mathrm{~N}$ & 1507 & 1439 \\
\hline \multicolumn{2}{l}{ Note: 'Orthodox' answers in italics } \\
\hline
\end{tabular}

Table 10: Axiom 4

numerical and verbal questions, and only one sixth agrees with the axiom in both questions simultaneously. In fact, when cross-checking the responses from the numerical and the verbal questions, consistent rejection of the axiom is the option that gathers the largest support (44\%). The importance-ofthe-income-of-the-poorest-individual' effect outlined above could be an explanation. Note that in the verbal question 20 our "justification" or "explanation" for a decrease (option b) is that the lowest income group disappears; and when explanations are dropped from the answers, the 'decrease' response loses strength: 15 percentage points that could be attributed to the 'importance-of-the-income-of-the-poorest-individual' effect. Furthermore, in the numerical question 8 , the poorest group in distribution A could be identified with individuals belonging to the richest one in distribution B.

\subsection{On the relevance of isolated individuals}

Consider now the issue of whether small groups or isolated individuals are insignificant in terms of polarisation - compare panels (a) and (b) in Figure $2 .{ }^{12}$ The message that comes out of the answers to questions $1,13 \mathrm{a}$ and

\footnotetext{
${ }^{12}$ This is taken from Figure 3 in Esteban and Ray (1994).
} 
13b - shown in Table 3 - seems to be clear-cut: few individuals do make a difference. Notwithstanding this, notice that 1 individual in 10 can be viewed as substantial part of society if seen as being $10 \%$ of the population or as an isolated individual if interpreted from the absolute perspective. Likewise, in the verbal question "few" is certainly not "very few", which admittedly would capture rather better the essence of what an "isolated individual" is.

(a)

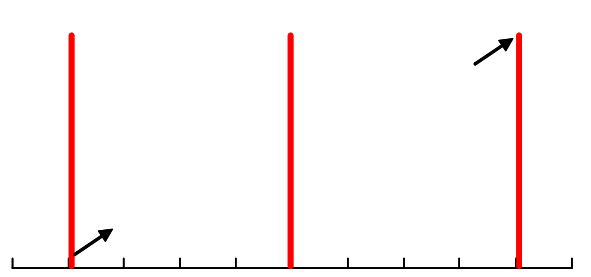

(b)

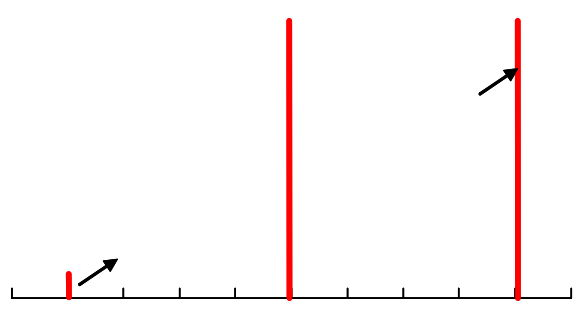

Figure 2: Insignificance of small groups

\subsection{Non-monotonicity}

Esteban and Ray (1994) argue that in Figure $1^{13}$ polarisation does not behave monotonically as population moves to the extremes from two central masses, and provided that initial polarisation is rather large. The reported support for the Axiom 5 above implies that the support for this feature should be rather weak. Indeed this is what we find. The interesting transition in Figure 1 - from panels (a) to (b) - is captured by our question 9 . Since there is no ground to allow for polarisation to decrease in the transition from panels (b) to (c), a non-monotonic behaviour implies that people should perceive a decrease in polarisation in the transformation going from panels (a) to (b). Now, only about one third of the sample considers that such a transformation implies a decrease in polarisation - see Table 11. Additional evidence in the same direction is provided by the responses to the same question 1 which was used to analyse people's support for Axiom 5 (Increased Spread). Here, again only about one third of the sample considers that a small outward movement away from one of the poles decreases polarisation. The verbal question 21 also tackles this point. The responses in favour of non-monotonicity amount to a mere $32 \%$ of the sample - monotonicity attracting more than half of the whole sample. Cross-checking the responses to questions 9 and 21 shows complete

\footnotetext{
${ }^{13}$ This is their Figure 5 (p.828).
} 


\begin{tabular}{lrllr}
\hline \hline \multicolumn{2}{c}{ Question 9} & & \multicolumn{2}{c}{ Question 21 } \\
\cline { 1 - 2 } Increases & 56.2 & & Increases always & 42.5 \\
Same & 6.7 & & Decreases always & 8.5 \\
Decreases & 37.1 & & Increases first, then decreases & 12.1 \\
& & & Decreases first, then increases & 20.3 \\
& & Same & 9.5 \\
& & None & 7.1 \\
$\mathrm{~N}$ & 1498 & $\mathrm{N}$ & 1415 \\
\hline \multicolumn{2}{l}{ Note: 'Orthodox' answers in italics } \\
\hline
\end{tabular}

Table 11: Non-Monotonicity in Figure 5

consistency between the numerical and the verbal questions. Finally, adding the responses to question 1 halves the above support to $5 \%$.

\section{Polarisation and inequality}

It is clear that the results on polarisation perceptions, particularly those reported in section 5.2, warrant a more detailed study. If respondents appear to reject the principle of Increased Bipolarity then this is an issue that cannot be just lightly set aside. There appear to be two main questions arising from this result: (a) Do people respond to polarisation questions as though they were being presented with issues in inequality? (b) Is it inappropriate to see the Increased Bipolarity principle as a proxy for the ER1 principle? To address these questions we carried out two follow-up studies that are discussed in Sections 6.1 and 6.2.

\subsection{Do respondents think in terms of inequality?}

Our findings suggest that important axioms which serve to differentiate polarisation from inequality - e.g. Increased Bipolarity - as well as other distinctive features of polarisation, i.e. the non-monotonic behaviour attributed to polarisation, are not widely accepted. Moreover, the answers obtained are those to be expected in the neighbouring field of inequality. These findings may indicate that respondents think in terms of inequality when answering our polarisation questionnaire. We investigated whether this is so by running a small follow-up experiment, which consists of using two parallel 


\begin{tabular}{ccc}
\hline \hline \multicolumn{3}{l}{ Responses in both questionnaires... } \\
... ought to & \multicolumn{2}{c}{... actually } \\
\hline \multirow{2}{*}{ Coincide } & Coincide & Differ \\
\cline { 2 - 3 } Differ & $I$ & $I I$ \\
\hline \hline
\end{tabular}

Table 12: Combinations of actual and expected answers in the polarisation and inequality questionnaires

questionnaires, one on polarisation and another one on inequality. The latter, results from replacing the word polarisation with inequality in the "bareverbal questions' version of the polarisation questionnaire (and adapting the introductory text).

To assess whether respondents think in terms of inequality when answering the polarisation questionnaire, we compare responses between the two samples; the full details of the comparative study are provided in Appendix B. As Table 12 shows, actual and expected responses can either coincide or differ between questionnaires. When disagreement between expectations and realisations (cells $I I$ and $I I I$ in Table 12) occurs because polarisation responses are not in line with the relevant axiom but inequality responses are, we will consider that respondents think in terms of inequality when answering the polarisation questionnaire. ${ }^{14}$ Responses that fall in cell $I V$, however, may reveal that individuals are indeed thinking differently in each questionnaire. ${ }^{15}$ Finally, notice that no information can be elicited from cell $I$, which describes the situation where responses ought to and indeed coincide in both questionnaires.

As shown in Table 13, ${ }^{16}$ expected answers differ in $40 \%$ of the questions, and most notably in those referring to Axiom 6 (Increased Bipolarity) (ques-

\footnotetext{
${ }^{14}$ Note that disagreement between expected and actual responses may also arise because inequality responses are not in line with the axiom and polarisation responses are, or because both inequality and polarisation responses are not in line with the respective relevant axioms. These two instances however do not provide any relevant information.

${ }^{15}$ That is, if answers differ because they are in line with the axiom. The case where answers happen to differ, but only because some of the responses do not accord with the relevant axiom does not provide any relevant information.

${ }^{16}$ In most cases the expected answer comes from adapting the polarisation axiom which is being tested to the case of inequality. Scale and translation invariance of questions 4 , 16, 5 and 17 are good examples of this. When this is does not apply, the expected answer uses the Principle of transfers. Only in the case of four questions have we appealed to stochastic dominance. In questions 6 and 18, distribution B generalised-Lorenz dominates
} 
tions 2 and 14) and to the non-monotonic behaviour of polarisation (questions 9 and 21). The answers obtained in question 2 may suggest that individuals think in terms of inequality when answering the polarisation questionnaire. Answers to this question ought to be different but, as shown in the appendix table 24 , they are actually very similar (cell $I I I$ ): in both questionnaires more than half of the respondents choose distribution B as the most polarised or unequal. Notwithstanding that, responses to the companion verbal question 14 do not go in the same direction, and thus cast doubt on the robustness of the previous conclusion.

The responses to questions 9 and 21 also provide inconclusive evidence. Answers to question 9 should differ between both questionnaires. On the one hand, and according to the principle of transfers, distribution A should be more unequal, while the non-monotonic behaviour of polarisation would require distribution $\mathrm{B}$ to show more polarisation. Respondents to the inequality questionnaire do answer in line with the principle of transfers, but on the polarisation side both distributions gather similar support - the difference in appendix table 29 not being statistically significant $(z=4.2 ; p$-value $<0.001)$ -, and support for distribution $\mathrm{A}$ is not as strong as it is among inequality respondents. Answers to the companion verbal question 21 give support to the possibility that polarisation-questionnaire respondents think in terms of inequality: irrespective of the questionnaire type the option that receives most support is that of a monotonic increase, consistent with inequality postulates but not with the non-monotonicity feature of polarisation. However, this conclusion is worth qualifying since the difference between monotonicity and non-monotonicity is much smaller in the polarisation sample than in the inequality sample.

Questions 6 and 18 are an interesting case, which suggests that respondents do not think in terms of inequality when confronted with the polarisation questions. Responses in both questionnaires are in line with Axiom 2, thus being clearly at odds with the (demanding) set of axioms required by the generalised Lorenz dominance criteria. However, responses to questions 8 and 20 are consistent with the hypothesis that individuals do think in terms of inequality.

\subsection{Increased Bipolarity - a closer look}

Our second response to the problem raised by the lack of support for the key Increased Bipolarity principle is to distinguish more sharply between Axiom

distribution A, while in questions 8 and 20 distribution B Lorenz dominates distribution A. 


\begin{tabular}{|c|c|c|c|c|c|}
\hline \multirow[b]{2}{*}{$\mathrm{Q}$} & \multicolumn{5}{|c|}{ Expected answer in... } \\
\hline & polarisation & inequality & $\mathrm{Q}$ & polarisation & inequality \\
\hline 1 & $\mathrm{~A}$ & $\mathrm{~A}$ & $13 a$ & $\mathrm{C}$ & $\mathrm{C}$ \\
\hline 2 & $A$ & $B$ & $13 \mathrm{~b}$ & B & B \\
\hline 3 & $\mathrm{AB}$ & $\mathrm{AB}$ & 14 & $B$ & $A$ \\
\hline 4 & $\mathrm{AB}$ & $\mathrm{AB}$ & 15 & $\mathrm{C}$ & $\mathrm{C}$ \\
\hline 5 & $\mathrm{AB}$ & $\mathrm{AB}$ & 16 & $\mathrm{~A}$ & A \\
\hline 6 & $B$ & $A$ & 17 & B & $\mathrm{B}$ \\
\hline 7 & B & B & 18 & $A$ & $B$ \\
\hline 8 & $B$ & $A$ & 19 & $\mathrm{~A}$ & $\mathrm{~A}$ \\
\hline 9 & $B$ & $A$ & 20 & $A$ & $B$ \\
\hline 10 & $\mathrm{~A}$ & $\mathrm{~A}$ & 21 & $D$ & $A$ \\
\hline
\end{tabular}

Table 13: Expected answers in the polarisation and inequality questionnaires

1 and Axiom 6. This was done by presenting a sample of 191 students with the inequality and polarisation versions of the questionnaire in Appendix $\mathrm{C}$ and comparing the results of questions 2 and 14 on the one hand with those of questions 11, 12 and 22 on the other.

Our analyses on the new sample confirm the weak support for Axiom 6 obtained with previous samples, but provide some evidence in support of Axiom $1 .{ }^{17}$ Thus, people seem to appreciate the differences between the two axioms.

As regards the new evidence on Axiom 1, the polarisation subsample (ca. 100 new respondents) answer questions 11 and 12 in accordance with Axiom 1 - nearly $50 \%$ of the respondents report that the pooling of the two small population masses increases polarisation - see Table 14. Moreover, the symmetry in the answers to questions 11 and 12 reveals support for a possible extension of Axiom 1 to include pooling on the lower income rungs, since strictly speaking, only question 11 provides a faithful representation of Axiom 1 - i.e. pooling of the masses on the upper income rungs. ${ }^{18}$

As pointed out above, Axioms 1 and 6 are key principles that distinguish the concepts of polarisation and inequality - their characterisation of a change in income distribution are, in a sense, in direct opposition to that the principle of transfers. Hence, it is worth noting that the respondents to the inequality questionnaire, provide answers to questions 11 and 12 which are consistent with the principle of transfers.

\footnotetext{
${ }^{17}$ The new follow-up sample provides answers to questions 2 and 14 which are very similar to those obtained with the other two samples - see Section 5.2.

${ }^{18}$ Though Axiom 1 gathers reasonable support for each of the two questions 11 and 12 separately, only $36 \%$ of respondents provide a consistent answer for both questions.
} 
Notwithstanding all this, the message coming from the answers to question 22 is less clear-cut since the three choices obtain roughly speaking the same (one third) support, irrespective of the type of questionnaire (polarisation or inequality).

\begin{tabular}{|c|c|c|c|}
\hline \multicolumn{4}{|c|}{ Polarisation } \\
\hline & Question 11 & Question 12 & Question 22 \\
\hline Increases & 46.9 & 48.5 & 33.3 \\
\hline Same & 17.4 & 23.7 & 34.4 \\
\hline Decreases & 35.7 & 27.8 & 32.3 \\
\hline $\mathrm{N}$ & 98 & 97 & 93 \\
\hline \multicolumn{4}{|c|}{ Inequality } \\
\hline & Question 11 & Question 12 & Question 22 \\
\hline Increases & 15.0 & 23.7 & 24.1 \\
\hline Same & 26.9 & 34.4 & 37.9 \\
\hline Decreases & 58.1 & 41.9 & 38.0 \\
\hline $\mathrm{N}$ & 93 & 93 & 87 \\
\hline
\end{tabular}

Table 14: Responses on questions dealing with Axiom ER1

\subsection{Axioms required by polarisation indices}

Only a minor proportion of the sample seems to endorse all the axioms required to build the most popular indices in the literature. The three axioms used in Theorem 1 in Esteban and Ray (1994) (questions 11, 6 and 7) gather $39 \%$ of support. When Axiom 4 is also considered - having thus the four axioms required to arrive at the preferred measure in Esteban and Ray (1994), theorem 3 - support goes down to $23 \%$. As far as Chakravarty and Majumdar (2001) is concerned, we can only test for three of the six axioms used in their Proposition 1 -questions 1 to 3 . None the less, our test on these three axioms provides little support. Hence, proposition 1 is very likely to enjoy very little support.Finally, consistency of the responses is virtually zero if tested by means of checking whether their answers comply with the three axioms used in Esteban and Ray (1994) (Theorem 1) to derive $P^{\alpha}$ and the property that polarisation should not be monotonic in situations such as that posed in Figure $1 .^{19}$

\footnotetext{
${ }^{19}$ This result is obtained when the non-monotonicity in Figure 1 is assessed by means of three numerical questions (1,9 and 10) and verbal question 21, which is a rather
} 


\section{What affects polarisation perceptions?}

Are individual characteristics or circumstances, such as the country of residence or parental income, important to understand the perception people have of polarisation? Or is it rather (the result of) certain individual choices like the subject of study what drive their perceptions? Maybe it is nothing to do with them but to their responses to different ways of eliciting their perceptions, such as the way questions are posed or presented or the means used to do so (i.e. on paper or virtually and by Internet).

In order to examine the extent to which reported polarisation perceptions depend on all those aspects, we followed a fourfold strategy. We asked all respondents to give us some basic information about themselves, we have run the questionnaire in six countries and in three different languages, we posed numerical and verbal questions, and finally we have also employed three versions of the questionnaire. We investigate what affects polarisation perceptions by means of multinomial regressions - one for each of the nineteen questions. Relative risk ratio estimates are shown in Tables 15 to $22 .{ }^{20}$

The way questions are presented some times influences polarisation perceptions. As pointed out above in the analysis of the axioms, the relationship between the answers given to numerical and verbal questions is rather loose for many questions. None the less, most times such (quantitative) discrepancies do not alter the qualitative conclusion. Perhaps not surprisingly, the way numerical questions are presented - with hints, with no hints, or by means of pictures - seems to influence the answers to some numerical questions. Interestingly, the type of questionnaire has a significant impact on the answers to the questions related to the axioms that receive the least support, i.e. questions 2 (Axiom 6), 4 (Axiom 9), 8 (Axiom 4), and 9 (Non-monotonicity feature). Take increased bipolarity; respondents answering the pictorial version of the questionnaire are twice as likely to agree with the axiom than those who answered either of the two non-pictorial versions; but even among those who had the pictorial version those who responded in accordance with the axiom were in a minority $(37 \%)$. They are also more than twice as likely to reject scale invariance in favour of reporting larger polarisation as the income gap between two poles remains constant in relative but increases in absolute terms. On the contrary, individuals who answered a questionnaire with no visual hints behave the opposite way. That is, they are twice as likely to reject scale invariance in favour of reporting smaller polarisation when the

demanding condition. The same result obtains if only the verbal question is used to assess the non monotonous behaviour of polarisation. However, when this condition is relaxed to the numerical questions only, support increases to $13 \%$.

${ }^{20}$ Estimates are obtained using the main sample only. 
income gap between two poles remains constant in relative but increases in absolute terms (question 4).

As explained above, translation invariance is favoured over scale invariance. The regression estimates on question 5 reveal that those who faced the pictorial version of the questionnaire are twice as likely to give support to the translation invariance axiom than to reporting a decrease in polarisation as the income gap increases in absolute terms but decreases in relative ones. Amongst those who reject Axiom 4, the questionnaire with no visual hints seems to induce individuals to think that the position of intermediate poles matter for polarisation. Finally, both questionnaires with pictures and no hints have a positive impact on the likelihood that the non-monotonic behaviour of polarisation in the transition of two poles getting closer or further apart be shared.

The type of questionnaire affects also the answer to questions that test axioms which gather large support. For instance, individuals who answered to pictorial version of the questionnaire are also more likely to agree with Axiom 2 than those who used the questionnaire with visual hints. In sum, influence of the type of questionnaire on perceptions does not show any systematic pattern; in particular, for some questions the pictorial version of the questionnaire seems to exert an influence in line with the axiom, while for some other questions the influence goes in the opposite direction. Moreover, the presentation of the numerical questions also seems to influence the answer to some verbal questions - which, recall, are identical across type of questionnaire.

Some of our respondents answered the questionnaire by internet using the Virtual Lab. The advantages of the Virtual Lab are many, but we should make sure that it does not systematically affect individual perceptions. Indeed, this is the overall conclusion which could be drawn from our multinomial estimates since the internet variable is only significant for some few cases.

Previous studies show that when it comes to reporting one's perceptions to distributive concepts such as inequality or poverty cultural background matters (Amiel and Cowell 1992, 1999b). We capture cultural differences by the subject of study and the country/language in which the questionnaire was run. Instruction in economics matters for one of the important axioms that gathered little support, increased bipolarity. As compared to individuals being taught other social sciences, economics students are far more inclined to think in accordance with the axiom, instead of reporting that an equalising transfer decreases polarisation. However, when answering question 16 - to test scale and translation invariance - , social science students are more likely to answer against both axioms. Here, social science students may be 
influenced (more than other students) by the poverty-related explanation provided in the answer choice - where it is suggested that doubling incomes may cover basic needs of low-income groups. Students from other disciplines are also more inclined than economics students to give answers that are not consistent with the axioms (questions 1, 3, 6, 9, 10).

In order to examine the influence of societies and the common features of their culture on individual perceptions of polarisation we have defined a variable - which is a combination of the language used and the place the questionnaire was run - that identifies Catalan, Spanish, Anglo-Saxon in England, the US and Australia, Uruguayan and Turkish. Students belonging to these cultures do not respond differently to the numerical questions that test the axioms that receive the least support (e.g. questions 2, 4, 8 and 9). As concerns the verbal questions, the most remarkable feature is the persistency of the Turkish respondents in providing answers that differ from those of the other groups. 


\begin{tabular}{|c|c|c|c|c|c|c|c|c|c|c|}
\hline "orthodox" answer & $\overline{\mathrm{A}}$ & & $\overline{\mathrm{A}}$ & & $\overline{\mathrm{AB}}$ & & $\mathrm{AB}$ & \multicolumn{3}{|c|}{$\overline{\mathrm{AB}}$} \\
\hline \multirow[t]{2}{*}{ Question } & 1 & & 2 & & 3 & & 4 & & 5 & \\
\hline & $\begin{array}{l}\text { RRR } \\
\text { AB }\end{array}$ & p-value & $\begin{array}{r}\mathrm{RRR} \\
\mathrm{A}\end{array}$ & p-value & $\begin{array}{r}\mathrm{RRR} \\
\mathrm{A}\end{array}$ & $\mathrm{p}$-value & $\begin{array}{r}\mathrm{RRR} \\
\mathrm{A}\end{array}$ & $\mathrm{p}$-value & $\begin{array}{r}\mathrm{RRR} \\
\mathrm{A}\end{array}$ & $p$-value \\
\hline Age & 1.07 & 0.02 & 1.02 & 0.30 & 0.97 & 0.29 & 0.99 & 0.63 & 1.03 & 0.07 \\
\hline Male & 0.68 & 0.13 & 1.13 & 0.37 & 1.15 & 0.45 & 0.90 & 0.63 & 1.80 & 0.00 \\
\hline $\begin{array}{l}\text { Employed } \\
\text { Subject study }\end{array}$ & 0.73 & 0.25 & 1.28 & 0.08 & 1.69 & 0.01 & 1.80 & 0.01 & 1.08 & 0.60 \\
\hline Business & 1.39 & 0.31 & 0.97 & 0.84 & 1.55 & 0.07 & 1.39 & 0.22 & 1.21 & 0.28 \\
\hline Social Sciences & 0.91 & 0.83 & 0.58 & 0.02 & 1.50 & 0.20 & 0.83 & 0.65 & 1.23 & 0.36 \\
\hline Other & 0.76 & 0.74 & 0.58 & 0.11 & 2.98 & 0.01 & 2.88 & 0.01 & 1.12 & 0.76 \\
\hline Language & & & & & & & & & & \\
\hline English & 1.43 & 0.38 & 1.39 & 0.14 & 4.26 & 0.00 & 2.02 & 0.02 & 1.84 & 0.01 \\
\hline Spanish & 1.03 & 0.93 & 1.41 & 0.07 & 1.14 & 0.62 & 0.76 & 0.39 & 0.90 & 0.60 \\
\hline Uruguayan & 0.97 & 0.95 & 1.32 & 0.24 & 1.61 & 0.17 & 0.92 & 0.85 & 1.67 & 0.03 \\
\hline English (Turkey) & 0.41 & 0.41 & 0.95 & 0.88 & 5.48 & 0.00 & 0.37 & 0.35 & 1.77 & 0.09 \\
\hline Version & & & & & & & & & & \\
\hline No Hints & 1.01 & 0.97 & 1.09 & 0.63 & 1.28 & 0.30 & 1.82 & 0.03 & 1.09 & 0.61 \\
\hline Pictures & 2.34 & 0.01 & 1.85 & 0.00 & 1.16 & 0.52 & 1.31 & 0.31 & 0.46 & 0.00 \\
\hline Internet & 0.86 & 0.82 & 1.03 & 0.94 & 1.06 & 0.91 & 1.32 & 0.62 & 0.59 & 0.18 \\
\hline Political view & & & & & & & & & & \\
\hline Centre & 1.11 & 0.75 & 0.98 & 0.93 & 1.07 & 0.78 & 1.37 & 0.29 & 0.88 & 0.46 \\
\hline Right & 1.08 & 0.85 & 1.08 & 0.72 & 1.12 & 0.71 & 0.99 & 0.99 & 0.88 & 0.55 \\
\hline Income parents & & & & & & & & & & \\
\hline Middle & 0.94 & 0.85 & 1.30 & 0.13 & 1.39 & 0.17 & 1.02 & 0.95 & 0.98 & 0.91 \\
\hline High & 1.13 & 0.75 & 1.39 & 0.11 & 1.09 & 0.77 & 1.22 & 0.54 & 0.98 & 0.92 \\
\hline Mobility prospects & & & & & & & & & & \\
\hline Same as parents & 1.14 & 0.73 & 1.10 & 0.63 & 0.78 & 0.36 & 1.50 & 0.18 & 0.91 & 0.64 \\
\hline Better than parents & 1.07 & 0.86 & 1.37 & 0.13 & 0.88 & 0.64 & 1.10 & 0.77 & 0.77 & 0.20 \\
\hline
\end{tabular}

Table 15: Effect of individual characteristics on answers to questions 1 to 5 . Relative Risk Ratios (part 1) 


\begin{tabular}{|c|c|c|c|c|c|c|c|c|c|c|}
\hline \multirow{4}{*}{$\begin{array}{l}\text { "orthodox" answer } \\
\text { Question }\end{array}$} & \multicolumn{2}{|l|}{$\overline{\mathrm{A}}$} & \multicolumn{2}{|l|}{$\overline{\mathrm{A}}$} & \multicolumn{2}{|l|}{$\overline{\mathrm{AB}}$} & $\overline{\mathrm{AB}}$ & \multicolumn{3}{|c|}{$\overline{\mathrm{AB}}$} \\
\hline & 1 & & 2 & & 3 & & 4 & & \multicolumn{2}{|l|}{5} \\
\hline & RRR & $\mathrm{p}$-value & RRR & $\mathrm{p}$-value & RRR & $\mathrm{p}$-value & RRR & $\mathrm{p}$-value & RRR & $\mathrm{p}$-value \\
\hline & B & & $\mathrm{AB}$ & & B & & $\mathrm{AB}$ & & B & \\
\hline Age & 1.04 & 0.03 & 1.02 & 0.32 & 0.96 & 0.04 & 0.99 & 0.65 & 1.02 & 0.30 \\
\hline Male & 0.98 & 0.86 & 1.09 & 0.59 & 1.02 & 0.86 & 1.16 & 0.26 & 0.97 & 0.86 \\
\hline Employed & 0.82 & 0.14 & 1.20 & 0.30 & 1.35 & 0.04 & 0.89 & 0.44 & 1.35 & 0.08 \\
\hline \multicolumn{11}{|l|}{ Subject study } \\
\hline Business & 1.54 & 0.01 & 1.23 & 0.34 & 1.30 & 0.14 & 0.56 & 0.00 & 1.26 & 0.26 \\
\hline Social Sciences & 1.45 & 0.08 & 0.70 & 0.21 & 1.55 & 0.05 & 0.71 & 0.13 & 1.02 & 0.94 \\
\hline Other & 3.85 & 0.00 & 0.29 & 0.02 & 2.61 & 0.01 & 0.94 & 0.87 & 1.64 & 0.19 \\
\hline \multicolumn{11}{|l|}{ Language } \\
\hline English & 1.20 & 0.41 & 1.17 & 0.56 & 4.04 & 0.00 & 0.79 & 0.30 & 2.78 & 0.00 \\
\hline Spanish & 1.40 & 0.06 & 0.79 & 0.34 & 1.66 & 0.01 & 1.11 & 0.58 & 1.51 & 0.07 \\
\hline Uruguayan & 1.38 & 0.15 & 1.23 & 0.47 & 1.82 & 0.01 & 0.77 & 0.28 & 1.21 & 0.55 \\
\hline English (Turkey) & 2.54 & 0.00 & 0.67 & 0.40 & 6.24 & 0.00 & 1.19 & 0.59 & 0.99 & 0.98 \\
\hline \multicolumn{11}{|l|}{ Version } \\
\hline No Hints & 1.25 & 0.19 & 0.73 & 0.17 & 1.20 & 0.34 & 1.25 & 0.18 & 1.09 & 0.68 \\
\hline Pictures & 1.41 & 0.03 & 1.17 & 0.44 & 1.37 & 0.06 & 0.49 & 0.00 & 0.77 & 0.19 \\
\hline Internet & 0.70 & 0.33 & 1.24 & 0.62 & 1.12 & 0.77 & 1.32 & 0.47 & 0.83 & 0.68 \\
\hline \multicolumn{11}{|l|}{ Political view } \\
\hline Centre & 1.42 & 0.05 & 1.24 & 0.35 & 1.10 & 0.60 & 1.12 & 0.52 & 1.00 & 0.99 \\
\hline Right & 1.41 & 0.11 & 1.40 & 0.23 & 0.96 & 0.87 & 1.04 & 0.88 & 1.06 & 0.84 \\
\hline \multicolumn{11}{|l|}{ Income parents } \\
\hline Middle & 1.10 & 0.55 & 0.91 & 0.68 & 1.01 & 0.98 & 1.25 & 0.19 & 0.75 & 0.16 \\
\hline High & 0.96 & 0.86 & 1.02 & 0.95 & 0.98 & 0.93 & 1.07 & 0.75 & 0.78 & 0.31 \\
\hline \multicolumn{11}{|l|}{ Mobility prospects } \\
\hline Same as parents & 1.09 & 0.66 & 1.13 & 0.63 & 0.74 & 0.13 & 1.49 & 0.05 & 1.34 & 0.26 \\
\hline Better than parents & 1.06 & 0.76 & 1.05 & 0.86 & 0.74 & 0.15 & 1.39 & 0.11 & 1.05 & 0.86 \\
\hline
\end{tabular}

Table 16: Effect of individual characteristics on answers to questions 1 to 5 Relative Risk Ratios (part 2) 


\begin{tabular}{|c|c|c|c|c|c|c|c|c|c|c|}
\hline "orthodox" answer & $\overline{\mathrm{B}}$ & & $\overline{\mathrm{B}}$ & & $\overline{\mathrm{B}}$ & & $\overline{\mathrm{B}}$ & & $\overline{\mathrm{A}}$ & \multirow[b]{3}{*}{$\mathrm{p}$-value } \\
\hline \multirow[t]{2}{*}{ Question } & 6 & \multirow[b]{2}{*}{ p-value } & 7 & & \multicolumn{2}{|l|}{8} & \multicolumn{2}{|l|}{9} & 10 & \\
\hline & $\begin{array}{r}\text { RRR } \\
\mathrm{A}\end{array}$ & & $\begin{array}{r}\text { RRR } \\
\mathrm{A}\end{array}$ & $\mathrm{p}$-value & $\begin{array}{r}\text { RRR } \\
\mathrm{A}\end{array}$ & p-value & $\begin{array}{l}\text { RRR } \\
\text { AB }\end{array}$ & $\mathrm{p}$-value & $\begin{array}{l}\text { RRR } \\
\text { AB }\end{array}$ & \\
\hline Age & 0.90 & 0.00 & 0.94 & 0.01 & 1.05 & 0.22 & 1.00 & 0.88 & 1.01 & 0.76 \\
\hline Male & 0.79 & 0.12 & 1.16 & 0.34 & 1.14 & 0.70 & 0.79 & 0.33 & 0.92 & 0.69 \\
\hline Employed & 1.14 & 0.39 & 1.04 & 0.83 & 0.70 & 0.34 & 1.91 & 0.01 & 1.14 & 0.57 \\
\hline \multicolumn{11}{|l|}{ Subject study } \\
\hline Business & 1.27 & 0.22 & 0.88 & 0.52 & 0.77 & 0.55 & 1.21 & 0.55 & 0.80 & 0.44 \\
\hline Social Sciences & 1.69 & 0.04 & 0.81 & 0.47 & 1.04 & 0.95 & 0.90 & 0.82 & 1.12 & 0.76 \\
\hline Other & 1.43 & 0.34 & 2.68 & 0.00 & 0.65 & 0.62 & 1.34 & 0.62 & 4.89 & 0.00 \\
\hline \multicolumn{11}{|l|}{ Language } \\
\hline English & 1.18 & 0.51 & 1.46 & 0.13 & 1.97 & 0.17 & 1.71 & 0.16 & 0.94 & 0.87 \\
\hline Spanish & 1.62 & 0.02 & 1.72 & 0.01 & 0.81 & 0.67 & 1.56 & 0.19 & 1.71 & 0.07 \\
\hline Uruguayan & 0.72 & 0.29 & 0.93 & 0.81 & 0.46 & 0.29 & 0.90 & 0.82 & 0.66 & 0.32 \\
\hline English (Turkey) & 3.10 & 0.00 & 0.43 & 0.13 & 1.79 & 0.42 & 1.62 & 0.47 & 2.36 & 0.06 \\
\hline \multicolumn{11}{|l|}{ Version } \\
\hline No Hints & 0.70 & 0.06 & 1.03 & 0.87 & 2.05 & 0.14 & 0.88 & 0.72 & 1.14 & 0.68 \\
\hline Pictures & 0.66 & 0.02 & 1.00 & 0.98 & 2.09 & 0.12 & 2.07 & 0.01 & 1.97 & 0.01 \\
\hline Internet & 3.34 & 0.01 & 1.70 & 0.27 & 1.55 & 0.62 & 1.58 & 0.44 & 1.94 & 0.22 \\
\hline \multicolumn{11}{|l|}{ Political view } \\
\hline Centre & 1.35 & 0.14 & 1.12 & 0.59 & 1.58 & 0.37 & 0.83 & 0.55 & 1.27 & 0.43 \\
\hline Right & 0.91 & 0.70 & 0.72 & 0.22 & 1.16 & 0.82 & 0.74 & 0.45 & 1.27 & 0.51 \\
\hline \multicolumn{11}{|l|}{ Income parents } \\
\hline Middle & 0.82 & 0.28 & 0.90 & 0.61 & 0.69 & 0.38 & 1.14 & 0.69 & 1.05 & 0.86 \\
\hline High & 0.79 & 0.31 & 0.84 & 0.45 & 0.47 & 0.15 & 1.59 & 0.21 & 0.93 & 0.83 \\
\hline \multicolumn{11}{|l|}{ Mobility prospects } \\
\hline Same as parents & 1.16 & 0.53 & 0.94 & 0.81 & 1.29 & 0.65 & 1.40 & 0.41 & 1.23 & 0.56 \\
\hline Better than parents & 1.19 & 0.45 & 1.20 & 0.45 & 1.02 & 0.97 & 2.08 & 0.07 & 1.44 & 0.29 \\
\hline \multicolumn{11}{|c|}{ Reference group: female, not employed, studies economics, answers catalan questionnaire with } \\
\hline olitically & 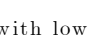 & & and & & & & & & & \\
\hline
\end{tabular}

Table 17: Effect of individual characteristics on answers to questions 6 to 10 . Relative Risk Ratios (part 1) 


\begin{tabular}{|c|c|c|c|c|c|c|c|c|c|c|}
\hline "orthodox" answer & $\overline{\mathrm{B}}$ & & $\overline{\mathrm{B}}$ & & $\overline{\mathrm{B}}$ & & $\overline{\mathrm{B}}$ & & $\overline{\mathrm{A}}$ & \multirow{4}{*}{$\mathrm{p}$-value } \\
\hline \multirow[t]{3}{*}{ Question } & 6 & & 7 & & 8 & & 9 & & 10 & \\
\hline & RRR & \multirow[t]{2}{*}{$\mathrm{p}$-value } & RRR & \multirow[t]{2}{*}{$\mathrm{p}$-value } & RRR & \multirow[t]{2}{*}{$\mathrm{p}$-value } & RRR & \multirow[t]{2}{*}{$\mathrm{p}$-value } & \multirow{2}{*}{$\begin{array}{r}\mathrm{RRR} \\
\mathrm{B}\end{array}$} & \\
\hline & $\mathrm{AB}$ & & $\mathrm{AB}$ & & B & & B & & & \\
\hline Age & 0.96 & 0.17 & 0.95 & 0.11 & 1.04 & 0.01 & 1.03 & 0.04 & 0.97 & 0.24 \\
\hline Male & 0.90 & 0.63 & 0.70 & 0.19 & 0.81 & 0.08 & 0.69 & 0.00 & 0.92 & 0.60 \\
\hline Employed & 1.24 & 0.36 & 4.41 & 0.00 & 0.81 & 0.10 & 0.92 & 0.54 & 1.34 & 0.10 \\
\hline Subject study & & & & & & & & & & \\
\hline Business & 1.12 & 0.71 & 0.99 & 0.97 & 1.02 & 0.88 & 1.15 & 0.39 & 1.56 & 0.04 \\
\hline Social Sciences & 0.76 & 0.53 & 1.10 & 0.83 & 0.97 & 0.87 & 1.43 & 0.08 & 1.25 & 0.48 \\
\hline Other & 4.11 & 0.01 & 0.41 & 0.42 & 2.40 & 0.00 & 1.85 & 0.05 & 3.85 & 0.00 \\
\hline Language & & & & & & & & & & \\
\hline English & 0.75 & 0.49 & 0.77 & 0.57 & 1.09 & 0.67 & 1.30 & 0.21 & 1.97 & 0.01 \\
\hline Spanish & 1.02 & 0.95 & 1.20 & 0.60 & 1.27 & 0.17 & 1.14 & 0.45 & 1.49 & 0.09 \\
\hline Uruguayan & 1.33 & 0.48 & 0.56 & 0.29 & 0.99 & 0.95 & 1.09 & 0.70 & 0.80 & 0.54 \\
\hline English (Turkey) & 2.16 & 0.16 & 0.00 & 1.00 & 1.33 & 0.37 & 1.70 & 0.10 & 1.59 & 0.34 \\
\hline Version & & & & & & & & & & \\
\hline No Hints & 0.90 & 0.72 & 0.51 & 0.05 & 1.06 & 0.71 & 1.68 & 0.00 & 1.16 & 0.49 \\
\hline Pictures & 0.76 & 0.31 & 0.60 & 0.10 & 1.11 & 0.50 & 1.57 & 0.00 & 0.83 & 0.37 \\
\hline Internet & 4.92 & 0.00 & 4.84 & 0.01 & 1.31 & 0.42 & 0.60 & 0.17 & 1.93 & 0.14 \\
\hline Political view & & & & & & & & & & \\
\hline Centre & 1.48 & 0.22 & 1.28 & 0.48 & 1.05 & 0.77 & 0.81 & 0.19 & 1.05 & 0.83 \\
\hline Right & 1.00 & 0.99 & 1.89 & 0.15 & 1.27 & 0.23 & 0.82 & 0.32 & 1.38 & 0.25 \\
\hline Income parents & & & & & & & & & & \\
\hline Middle & 1.18 & 0.58 & 0.73 & 0.35 & 0.91 & 0.53 & 0.85 & 0.32 & 0.99 & 0.95 \\
\hline High & 1.17 & 0.66 & 0.87 & 0.72 & 0.90 & 0.58 & 0.67 & 0.03 & 0.70 & 0.17 \\
\hline Mobility prospects & & & & & & & & & & \\
\hline Same as parents & 1.39 & 0.29 & 1.05 & 0.89 & 1.15 & 0.45 & 1.22 & 0.29 & 1.26 & 0.37 \\
\hline Better than parents & 0.95 & 0.89 & 0.93 & 0.85 & 1.03 & 0.86 & 0.99 & 0.97 & 1.03 & 0.90 \\
\hline
\end{tabular}

Table 18: Effect of individual characteristics on answers to questions 6 to 10 . Relative Risk Ratios (part 2) 


\begin{tabular}{|c|c|c|c|c|c|c|c|c|c|c|}
\hline "Orthodox" Answer & $\overline{\mathrm{C}}$ & & $\overline{\mathrm{B}}$ & & $\overline{\mathrm{C}}$ & & $\overline{\mathrm{A}}$ & & $\overline{\mathrm{B}}$ & \multirow{4}{*}{$\mathrm{p}$-value } \\
\hline \multirow[t]{3}{*}{ Question } & 13 & \multirow{3}{*}{ p-value } & 14 & & 15 & \multirow{3}{*}{$\mathrm{p}$-value } & 16 & \multicolumn{2}{|r|}{17} & \\
\hline & RRR & & RRR & p-value & RRR & & RRR & $\mathrm{p}$-value & RRR & \\
\hline & a & & $\mathrm{a}$ & & $\mathrm{a}$ & & b & & $\mathrm{a}$ & \\
\hline Age & 1.01 & 0.59 & 0.99 & 0.74 & 0.98 & 0.39 & 1.02 & 0.26 & 1.02 & 0.21 \\
\hline Male & 1.34 & 0.09 & 2.20 & 0.00 & 1.37 & 0.07 & 1.68 & 0.00 & 2.19 & 0.00 \\
\hline Employed & 1.01 & 0.97 & 1.03 & 0.86 & 1.01 & 0.96 & 0.95 & 0.72 & 1.08 & 0.65 \\
\hline \multicolumn{11}{|l|}{ Subject study } \\
\hline Business & 1.06 & 0.81 & 0.88 & 0.45 & 0.86 & 0.51 & 1.16 & 0.39 & 1.14 & 0.51 \\
\hline Social Sciences & 0.82 & 0.53 & 0.97 & 0.88 & 0.92 & 0.79 & 0.90 & 0.63 & 1.37 & 0.20 \\
\hline Other & 2.02 & 0.10 & 0.34 & 0.00 & 1.64 & 0.23 & 0.73 & 0.36 & 0.52 & 0.08 \\
\hline \multicolumn{11}{|l|}{ Language } \\
\hline English & 1.06 & 0.84 & 1.57 & 0.04 & 1.00 & 1.00 & 1.12 & 0.60 & 2.73 & 0.00 \\
\hline Spanish & 1.22 & 0.41 & 0.68 & 0.04 & 1.09 & 0.73 & 0.75 & 0.13 & 0.69 & 0.10 \\
\hline Uruguayan & 1.03 & 0.92 & 0.87 & 0.57 & 0.83 & 0.57 & 0.88 & 0.58 & 1.50 & 0.13 \\
\hline English (Turkey) & 0.99 & 0.99 & 1.93 & 0.08 & 2.80 & 0.01 & 0.94 & 0.89 & 0.95 & 0.92 \\
\hline \multicolumn{11}{|l|}{ Version } \\
\hline No Hints & 0.93 & 0.78 & 1.02 & 0.91 & 0.67 & 0.10 & 0.66 & 0.02 & 1.31 & 0.17 \\
\hline Pictures & 1.67 & 0.02 & 0.99 & 0.96 & 0.97 & 0.89 & 0.86 & 0.34 & 0.80 & 0.23 \\
\hline Internet & 1.61 & 0.29 & 0.85 & 0.68 & 1.39 & 0.52 & 1.78 & 0.13 & 0.36 & 0.04 \\
\hline \multicolumn{11}{|l|}{ Political view } \\
\hline Centre & 1.28 & 0.31 & 0.78 & 0.16 & 0.93 & 0.76 & 0.89 & 0.49 & 1.09 & 0.66 \\
\hline Right & 1.44 & 0.21 & 0.63 & 0.04 & 0.77 & 0.37 & 1.20 & 0.41 & 0.84 & 0.49 \\
\hline \multicolumn{11}{|l|}{ Income parents } \\
\hline Middle & 1.28 & 0.29 & 1.08 & 0.66 & 1.39 & 0.16 & 0.63 & 0.01 & 0.82 & 0.32 \\
\hline High & 0.99 & 0.98 & 1.17 & 0.46 & 1.59 & 0.09 & 1.07 & 0.73 & 0.88 & 0.59 \\
\hline \multicolumn{11}{|l|}{ Mobility prospects } \\
\hline Same as parents & 0.89 & 0.67 & 0.82 & 0.32 & 0.62 & 0.07 & 1.05 & 0.81 & 1.74 & 0.02 \\
\hline Better than parents & 0.92 & 0.75 & 0.88 & 0.53 & 1.06 & 0.82 & 0.97 & 0.90 & 1.26 & 0.36 \\
\hline
\end{tabular}

Table 19: Effect of individual characteristics on answers to questions 13 to 17. Relative Risk Ratios (part 1) 


\begin{tabular}{|c|c|c|c|c|c|c|c|c|c|}
\hline "Orthodox" Answer & \multicolumn{2}{|l|}{$\overline{\mathrm{C}}$} & \multicolumn{2}{|l|}{$\mathrm{B}$} & \multicolumn{2}{|l|}{$\mathrm{C}$} & \multicolumn{2}{|l|}{$\overline{\mathrm{A}}$} & \multirow{2}{*}{$\begin{array}{r}\mathrm{B} \\
17\end{array}$} \\
\hline \multirow[t]{2}{*}{ Question } & 13 & & 14 & & 15 & & 16 & & \\
\hline & $\begin{array}{r}\mathrm{RRR} \\
\mathrm{b}\end{array}$ & $\mathrm{p}$-value & $\begin{array}{r}\text { RRR } \\
\mathrm{b}\end{array}$ & p-value & $\begin{array}{r}\mathrm{RRR} \\
\mathrm{b}\end{array}$ & p-value & $\begin{array}{r}\text { RRR } \\
\mathrm{C}\end{array}$ & $\mathrm{p}$-value & $\begin{array}{r}\text { RRR } \\
\mathrm{C}\end{array}$ \\
\hline Age & 1.04 & 0.08 & 0.99 & 0.72 & 1.00 & 0.93 & 1.00 & 0.90 & 0.97 \\
\hline Male & 0.98 & 0.91 & 1.38 & 0.05 & 1.40 & 0.25 & 1.98 & 0.00 & 1.65 \\
\hline Employed & 0.75 & 0.15 & 1.29 & 0.14 & 0.88 & 0.67 & 0.94 & 0.78 & 1.71 \\
\hline Subject study & & & & & & & & & \\
\hline Business & 1.52 & 0.11 & 1.23 & 0.34 & 3.62 & 0.00 & 2.44 & 0.00 & 0.79 \\
\hline Social Sciences & 0.84 & 0.56 & 0.70 & 0.22 & 2.25 & 0.16 & 2.48 & 0.01 & 0.95 \\
\hline Other & 2.28 & 0.06 & 0.98 & 0.95 & 7.12 & 0.00 & 1.56 & 0.32 & 1.81 \\
\hline Language & & & & & & & & & \\
\hline English & 1.29 & 0.42 & 2.54 & 0.00 & 0.95 & 0.92 & 1.64 & 0.12 & 2.29 \\
\hline Spanish & 0.78 & 0.38 & 0.94 & 0.81 & 0.45 & 0.07 & 0.55 & 0.04 & 1.16 \\
\hline Uruguayan & 3.46 & 0.00 & 2.65 & 0.00 & 1.08 & 0.90 & 0.71 & 0.41 & 2.54 \\
\hline English (Turkey) & 0.92 & 0.89 & 2.74 & 0.03 & 7.50 & 0.00 & 5.87 & 0.00 & 7.91 \\
\hline Version & & & & & & & & & \\
\hline No Hints & 0.70 & 0.16 & 1.30 & 0.24 & 0.98 & 0.96 & 1.18 & 0.53 & 1.56 \\
\hline Pictures & 0.80 & 0.33 & 1.44 & 0.08 & 0.87 & 0.70 & 0.89 & 0.67 & 0.87 \\
\hline Internet & 1.27 & 0.63 & 1.23 & 0.63 & 1.33 & 0.69 & 1.87 & 0.23 & 2.11 \\
\hline Political view & & & & & & & & & \\
\hline Centre & 1.19 & 0.50 & 0.94 & 0.79 & 1.32 & 0.53 & 1.27 & 0.41 & 1.50 \\
\hline Right & 1.73 & 0.07 & 0.88 & 0.64 & 0.91 & 0.86 & 1.89 & 0.07 & 1.70 \\
\hline Income parents & & & & & & & & & \\
\hline Middle & 0.80 & 0.36 & 0.99 & 0.98 & 1.40 & 0.37 & 0.76 & 0.28 & 0.83 \\
\hline High & 0.92 & 0.77 & 1.34 & 0.24 & 1.34 & 0.52 & 0.72 & 0.30 & 0.65 \\
\hline Mobility prospects & & & & & & & & & \\
\hline Same as parents & 1.05 & 0.87 & 0.67 & 0.09 & 1.16 & 0.76 & 0.83 & 0.54 & 0.74 \\
\hline Better than parents & 0.99 & 0.98 & 0.70 & 0.14 & 2.01 & 0.14 & 0.96 & 0.90 & 0.81 \\
\hline
\end{tabular}

Table 20: Effect of individual characteristics on answers to questions 13 to 17. Relative Risk Ratios (part 2) 


\begin{tabular}{|c|c|c|c|c|c|c|c|c|}
\hline "Orthodox" Answer & $\overline{\mathrm{A}}$ & & $\overline{\mathrm{A}}$ & & $\overline{\mathrm{A}}$ & & $\overline{\mathrm{B}}$ & \multirow[b]{3}{*}{$p$-value } \\
\hline \multirow[t]{2}{*}{ Question } & 18 & \multirow[b]{2}{*}{$\mathrm{p}$-value } & 19 & \multirow[b]{2}{*}{$\mathrm{p}$-value } & 20 & \multicolumn{2}{|r|}{21} & \\
\hline & $\begin{array}{r}\mathrm{RRR} \\
\mathrm{b}\end{array}$ & & $\begin{array}{r}\mathrm{RRR} \\
\mathrm{b}\end{array}$ & & $\begin{array}{r}\text { RRR } \\
\mathrm{a}\end{array}$ & p-value & $\begin{array}{r}\mathrm{RRR} \\
\mathrm{b}\end{array}$ & \\
\hline Age & 0.94 & 0.03 & 0.96 & 0.22 & 1.04 & 0.04 & 0.98 & 0.32 \\
\hline Male & 0.69 & 0.03 & 1.31 & 0.23 & 1.10 & 0.47 & 0.76 & 0.04 \\
\hline Employed & 1.03 & 0.85 & 0.83 & 0.43 & 0.90 & 0.49 & 0.98 & 0.86 \\
\hline \multicolumn{9}{|l|}{ Subject study } \\
\hline Business & 0.82 & 0.35 & 3.05 & 0.00 & 0.78 & 0.16 & 1.16 & 0.39 \\
\hline Social Sciences & 0.75 & 0.35 & 1.16 & 0.75 & 0.97 & 0.88 & 1.30 & 0.23 \\
\hline Other & 1.26 & 0.57 & 3.45 & 0.01 & 0.75 & 0.40 & 1.53 & 0.20 \\
\hline \multicolumn{9}{|l|}{ Language } \\
\hline English & 1.07 & 0.80 & 1.63 & 0.16 & 1.85 & 0.00 & 0.85 & 0.48 \\
\hline Spanish & 0.88 & 0.58 & 0.45 & 0.03 & 1.13 & 0.53 & 1.02 & 0.92 \\
\hline Uruguayan & 0.39 & 0.01 & 1.07 & 0.89 & 1.25 & 0.34 & 1.04 & 0.87 \\
\hline English (Turkey) & 2.61 & 0.06 & 17.99 & 0.00 & 3.19 & 0.00 & 2.21 & 0.05 \\
\hline \multicolumn{9}{|l|}{ Version } \\
\hline No Hints & 1.07 & 0.78 & 1.08 & 0.80 & 0.90 & 0.55 & 0.92 & 0.66 \\
\hline Pictures & 1.91 & 0.00 & 1.07 & 0.80 & 0.89 & 0.47 & 0.94 & 0.73 \\
\hline Internet & 2.00 & 0.15 & 1.72 & 0.39 & 1.60 & 0.20 & 0.63 & 0.27 \\
\hline \multicolumn{9}{|l|}{ Political view } \\
\hline Centre & 0.92 & 0.69 & 1.26 & 0.48 & 0.81 & 0.23 & 1.26 & 0.20 \\
\hline Right & 0.69 & 0.19 & 1.12 & 0.77 & 0.80 & 0.30 & 1.39 & 0.14 \\
\hline \multicolumn{9}{|l|}{ Income parents } \\
\hline Middle & 0.79 & 0.26 & 1.02 & 0.95 & 1.20 & 0.31 & 1.08 & 0.66 \\
\hline High & 0.85 & 0.54 & 1.02 & 0.96 & 1.21 & 0.38 & 1.07 & 0.74 \\
\hline \multicolumn{9}{|l|}{ Mobility prospects } \\
\hline Same as parents & 0.92 & 0.75 & 1.27 & 0.49 & 1.01 & 0.96 & 0.95 & 0.81 \\
\hline Better than parents & 1.23 & 0.42 & 1.28 & 0.48 & 0.98 & 0.94 & 1.03 & 0.88 \\
\hline
\end{tabular}

Table 21: Effect of individual characteristics on answers to questions 18 to 21. Relative Risk Ratios (part 1) 


\begin{tabular}{|c|c|c|c|c|c|c|c|c|}
\hline "Orthodox" Answer & $\mathrm{A}$ & & $\bar{A}$ & & $\overline{\mathrm{A}}$ & & $\mathrm{B}$ & \multirow{4}{*}{$\mathrm{p}$-value } \\
\hline \multirow[t]{3}{*}{ Question } & 18 & & 19 & & 20 & & 21 & \\
\hline & RRR & p-value & $\mathrm{RRR}$ & $\mathrm{p}$-value & RRR & $\mathrm{p}$-value & RRR & \\
\hline & \multicolumn{2}{|l|}{$\mathrm{c}$} & \multicolumn{2}{|l|}{$\mathrm{c}$} & \multicolumn{2}{|l|}{$\mathrm{c}$} & $\mathrm{c}$ & \\
\hline Age & 0.97 & 0.34 & 0.96 & 0.12 & 1.02 & 0.45 & 0.96 & 0.15 \\
\hline Male & 1.27 & 0.23 & 0.83 & 0.28 & 0.96 & 0.84 & 0.83 & 0.37 \\
\hline Employed & 0.81 & 0.34 & 1.25 & 0.21 & 1.02 & 0.93 & 1.09 & 0.69 \\
\hline \multicolumn{9}{|l|}{ Subject study } \\
\hline Business & 1.39 & 0.22 & 1.33 & 0.19 & 1.48 & 0.17 & 1.41 & 0.23 \\
\hline Social Sciences & 1.13 & 0.73 & 1.06 & 0.85 & 1.18 & 0.65 & 2.47 & 0.01 \\
\hline Other & 2.20 & 0.09 & 1.70 & 0.21 & 3.51 & 0.01 & 1.18 & 0.80 \\
\hline \multicolumn{9}{|l|}{ Language } \\
\hline English & 0.86 & 0.66 & 0.93 & 0.79 & 1.00 & 1.00 & 0.94 & 0.86 \\
\hline Spanish & 0.65 & 0.14 & 0.99 & 0.95 & 1.05 & 0.88 & 1.38 & 0.26 \\
\hline Uruguayan & 1.00 & 0.99 & 0.81 & 0.50 & 1.44 & 0.35 & 0.98 & 0.97 \\
\hline English (Turkey) & 3.29 & 0.04 & 2.49 & 0.08 & 11.02 & 0.00 & 5.21 & 0.00 \\
\hline \multicolumn{9}{|l|}{ Version } \\
\hline No Hints & 0.74 & 0.25 & 1.08 & 0.72 & 0.91 & 0.74 & 0.99 & 0.96 \\
\hline Pictures & 0.77 & 0.28 & 0.81 & 0.30 & 0.77 & 0.31 & 1.02 & 0.94 \\
\hline Internet & 2.06 & 0.17 & 2.04 & 0.13 & 0.76 & 0.66 & 2.68 & 0.05 \\
\hline \multicolumn{9}{|l|}{ Political view } \\
\hline Centre & 1.14 & 0.64 & 1.36 & 0.18 & 0.85 & 0.56 & 1.01 & 0.97 \\
\hline Right & 1.15 & 0.69 & 1.53 & 0.14 & 1.04 & 0.91 & 0.79 & 0.53 \\
\hline \multicolumn{9}{|l|}{ Income parents } \\
\hline Middle & 0.87 & 0.61 & 1.15 & 0.52 & 0.62 & 0.06 & 0.89 & 0.66 \\
\hline High & 0.74 & 0.34 & 1.00 & 0.99 & 0.56 & 0.06 & 0.92 & 0.80 \\
\hline \multicolumn{9}{|l|}{ Mobility prospects } \\
\hline Same as parents & 1.22 & 0.49 & 1.16 & 0.55 & 2.01 & 0.03 & 0.89 & 0.71 \\
\hline Better than parents & 0.87 & 0.65 & 0.88 & 0.62 & 1.10 & 0.78 & 1.03 & 0.93 \\
\hline
\end{tabular}

Table 22: Effect of individual characteristics on answers to questions 18 to 21. Relative Risk Ratios (part 2) 


\section{A brief conclusion}

Do people view polarisation in the same way that economists do? In many respects, yes. But in one vital respect - the issue of Increased Bipolarity - they certainly do not. This point unfortunately undermines some of the standard approaches to polarisation that have been developed in the literature. What is more the conclusion is robust under alternative representations of the questionnaire (pictorial, numerical or verbal; with or without hints). However, this point should be qualified if one distinguishes between Increased Bipolarity and the related but more narrowly focused ER1 axiom of Esteban and Ray: it emerges that ER1 can claim greater support among our respondents than Increased Bipolarity but it is still only a minority whose views on polarisation are consistent with ER1. Moreover, the most popular indices in the literature do not enjoy much support since only a small proportion of people endorse all the axioms that these measures require.

Do people view polarisation in the same way that they view inequality? Here the evidence is mixed. The responses to some questions suggest that individuals do think in terms of inequality while some others point to the opposite conclusion. Either way it suggests that there may be room for new thinking on the meaning of polarisation.

\section{References}

Amiel, Y. and F. A. Cowell (1992). Measurement of income inequality: Experimental test by questionnaire. Journal of Public Economics 47 , $3-26$.

Amiel, Y. and F. A. Cowell (1999a). Income transformations and income inequality. In D. Slottje (Ed.), Advances in Econometrics, Income Distribution and Scientific Methodology, pp. 209-232. Heidelberg: Physica Verlag.

Amiel, Y. and F. A. Cowell (1999b). Thinking about Inequality. Cambridge: Cambridge University Press.

Bossert, W. and A. Pfingsten (1990). Intermediate inequality: concepts, indices and welfare implications. Mathematical Social Science 19, 117134 .

Bossert, W. and W. Schworm (2006). Measures of polarization. Working paper, Dt'epartment de Sciences Economiques and CIREQ, Universit é de Montr éal, C.P. 6128, succursale Centreville, Montr éal QC H3C 3J7, Canada. 
Chakravarty, S. R. and A. Majumdar (2001). Inequality, polarisation and welfare: Theory and applications. Australian Economic Papers 40, 1 13.

Dalton, H. (1920). Measurement of the inequality of incomes. The Economic Journal 30, 348-361.

Esteban, J., C. Gradin, and D. Ray (2007). An extension of a measure of polarization, with an application to the income distribution of five oecd countries. Journal of Economic Inequality 5, 1-19.

Esteban, J. and D. Ray (1994). On the measurement of polarization. Econometrica 62, 819-851.

Rodriguez, J. G. and R. Salas (2003). Exgtended bi-polarization and inequality measures. Research on Economic Inequality 9, 69-83.

Wang, Y.-Q. and K.-Y. Tsui (2000). Polarization orderings and new classes of polarization indices. Journal of Public Economic Theory 2, 349-363.

Wolfson, M. C. (1994). Conceptual issues in normative measurement when inequalities diverge. American Economic Review 84 (5), 353-358.

Wolfson, M. C. (1997). Divergent inequalities: theory and empirical results. Review of Income and Wealth 43, 401-421. 


\section{A The Increased Bipolarity axiom}

Consider the possible relationship between the apparently similar Axioms 1 (ER1) and 6 (Increased Bipolarity). We begin by noting two differences that make it difficult to compare the two axioms simply.

- First Chakravarty and Majumdar (2001) impose a "one-sidedness" condition in Axiom 6 in that the implied transfers must take place on one side or other of the median. If $\frac{1}{2} p_{1}>p_{2}$ in Esteban and Ray's discussion $^{21}$ then clearly the income change implied in Axiom 1 would take place above the median. But if $\frac{1}{2} p_{1}<p_{2}<p_{1}$ then the "one-sidedness" condition is violated.

- Second Esteban and Ray always work in terms of log-incomes while Chakravarty and Majumdar work only in terms of incomes. So the income change in Axiom 1 is not a pure transfer as it is in Axiom 6 (in ER1 the point masses are moved to the geometric mean of the two incomes, not the arithmetic mean). However it is interesting to note Esteban and Ray's remark that "any other scalar can be used as the basic perceptual variable." (p. 829). So it may be reasonable to consider a form of the principle in Esteban and Ray (1994) in terms of income rather than log-income.

In the light of these two points suppose we consider a modified form of Axiom 1 that imposes a stricter condition on $p_{1}$ and $p_{2}$ and that permits use of the arithmetic mean:

Axiom 10 (ER1 $*$ ) Let $\frac{1}{2} p_{1}>p_{2}=p_{3}$ and $x_{1}<x_{2}<x_{3}$. Then, for $p_{2} / p_{1}$ sufficiently small and $x_{3} / x_{2}$ sufficiently small:

$$
P\left(\left(p_{1}, 2 p_{2}\right),\left(x_{1}, \frac{1}{2}\left[x_{2}+x_{3}\right]\right)\right)>P(\mathbf{p}, \mathbf{x})
$$

Then it is clear that the conditions for ER $1^{*}$ are a special case of Increased Bipolarity. In other words if $P$ satisfies Increased Bipolarity then it must satisfy ER1*, but not vice versa. So it is clear that Axiom 6 implies Axiom 10 but that neither Axiom 1 nor Axiom 10 implies Axiom 6.

\footnotetext{
${ }^{21}$ Note that in the diagram that they use to illustrate the meaning of their Axiom 1 (p. 832 ). it is clear that $p_{1}>2 p_{2}$.
} 


\section{B Comparison of polarisation and inequality}

The following are the summary data for Follow-up study 1 (FU1) that explicitly compared results from almost-identical polarisation and inequality questionnaires.

\begin{tabular}{lrrrr}
\hline \hline & Question 1 & Question 13a & Question 13b & Question 10 \\
& \multicolumn{5}{c}{ Polarisation } \\
Increases & 59.1 & 55.4 & 70.8 & 64.9 \\
Same & 3.5 & 8.5 & 7.7 & 16.7 \\
Decreases & 37.4 & 24.6 & 14.6 & 18.4 \\
Depends & & 11.5 & 6.9 & \\
$\mathrm{~N}$ & 115 & 130 & 130 & 114 \\
& & & & \\
Increases & 75.5 & 78.0 & 82.0 & 73.9 \\
Same & 8.2 & 3.9 & 4.7 & 9.9 \\
Decreases & 16.4 & 10.2 & 9.4 & 16.2 \\
Depends & & 7.9 & 3.9 & \\
N & 110 & 127 & 128 & 111 \\
\hline Note: 'Orthodox' answers in italics & \multicolumn{4}{c}{} \\
\hline
\end{tabular}

Table 23: Increased Spread in FU1

\begin{tabular}{lcr}
\hline \hline & $\begin{array}{c}\text { Question 2 } \\
\text { Polarisation }\end{array}$ \\
Increases & 33.6 & 18.5 \\
Same & 14.7 & 63.1 \\
Decreases & 51.7 & 18.5 \\
$\mathrm{~N}$ & 116 & 130 \\
& & \\
& \multicolumn{2}{c}{ Inequality } \\
Increases & 31.8 & 9.5 \\
Same & 14.6 & 52.4 \\
Decreases & 53.6 & 38.1 \\
$\mathrm{~N}$ & 110 & 126 \\
\hline Note: 'Orthodox' answers in italics \\
\hline
\end{tabular}

Table 24: Increased Bipolarity in FU1 


\begin{tabular}{lcr}
\hline \hline & $\begin{array}{c}\text { Question 3 } \\
\text { Polarisation }\end{array}$ \\
Increases & 29.3 & 11.0 \\
Same & 56.9 & 78.7 \\
Decreases & 13.8 & 10.2 \\
$\mathrm{~N}$ & 116 & 127 \\
& & \\
& \multicolumn{2}{c}{ Inequality } \\
Increases & 27.36 & 12.6 \\
Same & 58.49 & 79.53 \\
Decreases & 14.15 & 7.87 \\
$\mathrm{~N}$ & 106 & 127 \\
\hline Note: 'Orthodox' answers in italics \\
\hline
\end{tabular}

Table 25: Population Principle in FU1

\begin{tabular}{lrrrr}
\hline & Question 4 & $\begin{array}{c}\text { Question 5 } \\
\text { Polarisation }\end{array}$ & Question 16 & Question 17 \\
Increases & 57.4 & 27.0 & 18.6 & 13.2 \\
Same & 32.2 & 48.7 & 69.0 & 57.4 \\
Decreases & 10.4 & 24.4 & 1.6 & 15.5 \\
Depends & & & 10.9 & 14.0 \\
N & 115 & 115 & 129 & 129 \\
& & Inequality & \\
Increases & 61.1 & 15.7 & 17.3 & 1.6 \\
Same & 31.5 & 49.1 & 70.1 & 67.5 \\
Decreases & 7.4 & 35.2 & 5.5 & 20.6 \\
Depends & & & 7.1 & 10.3 \\
N & 108 & 108 & 127 & 126 \\
\hline Note: 'Orthodox' answers in italics & \multicolumn{3}{c}{} \\
\hline
\end{tabular}

Table 26: Scale and Translation Invariance in FU1 


\begin{tabular}{lrcrr}
\hline \hline & \multicolumn{2}{c}{ Axiom 2 } & \multicolumn{2}{c}{ Axiom 3 } \\
& Question 6 & Question 18 & Question 7 & Question 19 \\
Pncreases & 67.5 & 53.2 & 64.9 & 48.4 \\
Same & 9.7 & 12.7 & 8.8 & 27.3 \\
Decreases & 22.8 & 19.1 & 26.3 & 14.8 \\
Depends & & 15.1 & & 9.4 \\
N & 114 & 126 & 114 & 128 \\
& & & & \\
Increases & 62.7 & 48.4 & 82.7 & 52.8 \\
Same & 12.7 & 15.1 & 5.5 & 26.8 \\
Decreases & 24.6 & 21.4 & 11.8 & 11.8 \\
Depends & & 15.1 & & 8.7 \\
N & 110 & 126 & 110 & 127 \\
\hline
\end{tabular}

Table 27: Axioms 2 and 3 in FU1

\begin{tabular}{lcr}
\hline \hline & $\begin{array}{c}\text { Question 8 } \\
\text { Polarisation }\end{array}$ \\
Increases & 40.7 & 32.5 \\
Same & 6.8 & 19.8 \\
Decreases & 52.5 & 47.6 \\
$\mathrm{~N}$ & 118 & 126 \\
& & \\
& \multicolumn{2}{c}{ Inequality } \\
Increases & 18.9 & 15.7 \\
Same & 9.0 & 24.0 \\
Decreases & 72.1 & 60.3 \\
$\mathrm{~N}$ & 111 & 121 \\
\hline Note: 'Orthodox' answers in italics \\
\hline
\end{tabular}

Table 28: Axiom 4 in FU1 


\begin{tabular}{|c|c|c|c|}
\hline \multirow{2}{*}{\multicolumn{2}{|c|}{ Question 9}} & \multicolumn{2}{|l|}{ Question 21} \\
\hline & & Polarisation & \\
\hline Increases & 49.6 & Increases always & 31.0 \\
\hline Same & 7.8 & Decreases always & 8.7 \\
\hline \multirow[t]{4}{*}{ Decreases } & 42.6 & Increases first, then decreases & 13.5 \\
\hline & & Decreases first, then increases & 18.3 \\
\hline & & Same & 18.3 \\
\hline & & None & 10.3 \\
\hline \multirow[t]{2}{*}{$\mathrm{N}$} & 115 & $\mathrm{~N}$ & 126 \\
\hline & & Inequality & \\
\hline Increases & 62.4 & Increases always & 38.7 \\
\hline Same & 5.5 & Decreases always & 9.2 \\
\hline \multirow[t]{4}{*}{ Decreases } & 32.1 & Increases first, then decreases & 9.2 \\
\hline & & Decreases first, then increases & 11.8 \\
\hline & & Same & 25.2 \\
\hline & & None & 5.9 \\
\hline $\mathrm{N}$ & 109 & $\mathrm{~N}$ & 119 \\
\hline
\end{tabular}

Table 29: Non-monotonicity in FU1 


\section{The questionnaires}

Following is an example of the pictorial version of the questionnaire used in the present study. All the variants used in the study can be found at http://darp.lse.ac.uk/polarisation/. 


\section{INCOME POLARISATION QUESTIONNAIRE}

This questionnaire concerns people's attitude to income polarisation. We would be interested in your views, based on hypothetical situations. Because it is about attitudes there are no "right" answers. Some of the possible answers correspond to assumptions commonly made by economists: but these assumptions may not be good ones. Your responses will help to shed some light on this, and we would like to thank you for your participation. The questionnaire is anonymous. Please do not write your name on it.

Alfaland is a small country for which two economic programmes have been proposed. It is known that the programmes will have an identical effect on the population - except in so far as incomes are concerned (all the people in Alfaland are identical in every respect other than income). In questions 1 to 10 you are asked about two alternative lists of incomes A and B (in Alfaland local currency) which result from each of these programmes. We have drawn attention to the parts where the lists differ by highlighting them in bold Please state which programme you consider would make the community of Alfaland more polarised by circling A or B. If you consider that each of the programmes would make the community equally polarised then circle both A and B.

1. $A=(5,10,10,10,10,50,50,50,50,50)$

2. $A=(7,8,10,10,10,50,50,50,50,50)$

3. $A=(10,10,10,10,10,50,50,50,50,60)$

4. $A=(10,10,10,10,10,50,50,50,50,50)$

5. $A=(10,10,10,10,10,50,50,50,50,50)$

6. $A=(10,10,10,10,10,70,70,100,100,100)$

7. $A=(10,10,10, \mathbf{5 0}, \mathbf{5 0}, \mathbf{5 0}, \mathbf{5 0}, 90,90,90)$

8. $A=(10,10,50,50,50,50,50,50,50$, $100,100,100,100,100)$

9. $A=(5,5,10,10,10,50,50,50,60,60)$

10. $A=(5,5,5,5,5,60,60,60,60,60)$

$$
\begin{aligned}
& B=(10,10,10,10,10,50,50,50,50,50) \\
& B=(5,10,10,10,10,50,50,50,50,50) \\
& B=(10,10,10,10,10,10,10,10,10,10,50,50, \\
&50,50,50,50,50,50,60,60)
\end{aligned}
$$$$
B=(20,20,20,20,20,100,100,100,100,100)
$$$$
B=(20,20,20,20,20,60,60,60,60,60)
$$$$
B=(10,10,10,10,10, \mathbf{9 0}, \mathbf{9 0}, 100,100,100)
$$$$
B=(10,10,10, \mathbf{1 0}, \mathbf{1 0}, \mathbf{9 0}, \mathbf{9 0}, 90,90,90)
$$$$
B=(50,50,50,50,50,50,50, \mathbf{1 0 0}, \mathbf{1 0 0} \text {, }
$$$$
100,100,100,100,100)
$$$$
B=(\mathbf{1 0}, \mathbf{1 0}, 10,10,10,50,50,50, \mathbf{5 0}, \mathbf{5 0})
$$

$B=(10,10,10,10,10,50,50,50,50,50)$ 
In each of the questions 11 to 19 you are presented with a hypothetical change and some views about that change. Please circle the letter alongside the view that corresponds most closely to your own. Feel free to add any comments which explain the reason for your choice.

11) Suppose there is a society consisting of two groups of people with many individuals in each group. One of the groups contains identical low-income people while the other group contains identical highincome people. If a few of the low-income individuals see their income drop by half, then:

a) Income polarisation decreases because society is no longer structured in two sharply defined groups

b) Income polarisation remains the same because one or very few individuals do not make any difference.

c) Income polarisation increases because the income difference between the poorest and the richest is now larger.

d) Whether income polarisation increases/decreases/remains the same depends on the level of income

Suppose that instead of a few low-income individuals seeing their income drop by half, a few highincome individuals see their incomes double. Then income polarisation ...

a) decreases.

b) increases.

c) remains unchanged.

d) may move either way, depending on the level of income.

In the light of the above would you want to change your answer to question 1 ? If so please write your new response ("A" or "B" or “A and B") here:

12) Suppose we transfer income from a person who has more income to a person who has less, without changing anyone else's income. The two persons belong either to the poorest $50 \%$ or to the richest $50 \%$, and after the transfer the person who formerly had more still has more. Income polarisation in this society...

a) has fallen because the person doing the transfer is further away after the transfer from the person who was immediately richer.

b) has increased because the two persons involved in the transfer are closer to each other after the transfer.

c) has not changed.

In the light of the above would you want to change your answer to question 2? If so please write your new response (" $A$ " or " $B$ " or " $A$ and $B$ ") here:

In each of the questions 13 to 15, consider a society with only two groups which have different levels of income. All high-income people have the same income and all low-income people also have the same income.

13) Suppose we replicate this society with an exact copy of itself. After the replication, income polarisation

a) increases because there is more people in each group.

b) decreases.

c) remains the same because the percentage of people in each group is the same as before.

In the light of the above would you want to change your answer to question 3 ? If so please write your new response (" $A$ ” or " $B$ ” or " $A$ and $B$ ”) here: 
14) Suppose we double the income of each person in the above society.

a) The two income groups have the same percentage of people and income share, and the relative income difference between the two groups has not changed, so income polarisation remains the same.

b) The income gap between the rich and the poor group has increased, so income polarisation has increased.

c) After doubling incomes the low-income group might have enough money for basic needs, so income polarisation has decreased.

d) Whether income polarisation increases/decreases/remains the same depends on the level of income

In the light of the above would you want to change your answer to question 4 ? If so please write your new response ("A" or " $\mathrm{B}$ " or "A and B") here:

15) Suppose we add the same fixed amount to the incomes of each person in the above society.

a) Income polarisation has fallen because the relative distance between the two groups has decreased.

b) Income polarisation remains the same because the absolute distance between the two groups has not changed.

c) Income polarisation has increased.

d) Whether income polarisation increases/decreases/remains the same depends on the level of income

In the light of the above would you want to change your answer to question 5 ? If so please write your new response ("A" or "B" or "A and B") here:

16) Consider a society with only three income groups where all persons within a group have the same income level. The first group is the most populated one and has the lowest income level. The second group is less populated than the first one but has the highest income level. The third group is the least populated one and has an intermediate income level, closer to the highest income level of the second group than to the lowest income level of the first group. Suppose we add some income to each person belonging to the third group.

a) Income polarisation increases because the third group is closer to the second group and further away from the first one, so the two least populated groups become closer to each other.

b) Income polarisation falls.

c) Income polarisation remains unchanged.

d) Whether income polarisation increases/decreases/remains the same depends on the levels of income in each group

In the light of the above would you want to change your answer to question 6? If so please write your new response ("A" or " $\mathrm{B}$ " or "A and B") here:

17) Consider a society with three income groups with similar population shares and where all persons within a group have the same income level. Suppose that half the population of the intermediate group moves to the lowest-income group and the other half moves to the highest-income one.

a) As the intermediate group disappears income polarisation increases

b) As the number of groups is smaller, income polarisation falls.

c) Income polarisation remains unchanged.

d) Whether income polarisation increases/decreases/remains the same depends on the levels of income in each group.

In the light of the above would you want to change your answer to question 7? If so please write your new response (" $\mathrm{A}$ " or " $\mathrm{B}$ " or "A and B") here: 
18) Consider a society with three income groups where all persons within a group have the same income level: the income gap between those in the lowest income group and the middle group is about the same as the gap between those in the middle group and the highest income group. The lowest income group has a very small population; the middle group has a very large population. Suppose we add to the incomes of lowest-income group people an amount that is so large that they are lifted to the level of the high-income group.

a) Income polarisation increases because there are now two sharply defined groups.

b) Income polarisation decreases because the lowest income group disappears.

c) Income polarisation does not change.

In the light of the above would you want to change your answer to question 8? If so please write your new response (“A” or "B” or “A and B") here:

19) Consider a society consisting of two groups of people with many individuals in each group. One of the groups contains identical low-income people while the other group contains identical high-income people. Suppose that one by one, low-income individuals become equally poorer and high-income individuals become equally richer. When half of the individuals have moved away from the original groups, the society has four income groups, and as individuals keep on moving the society ends up having once again two groups of identical poorer and richer people.

a) Income polarisation increases continuously because persons are systematically moving further away from each other

b) Income polarisation decreases continuously

c) Income polarisation at first increases and then decreases because at first the number of groups doubles and then halves.

d) Income polarisation at first decreases and then increases because at first the number of groups doubles and then halves.

e) Income polarisation remains the same throughout

f) None of the above.

In the light of the above would you want to change your answer to questions 1,9 and 10 ? If so please write your new responses here:

1:

9:

10:

Finally, we would be grateful for some information about yourself:

- $\quad$ Are you male or female?

- What is your age?

- What is your special subject of study?

- Were you employed before university?

- How would you rate your political views? Please put a $\sqrt{ }$ on this scale.

- How would you rate your family's income in 1995? Please put a $\sqrt{ }$ on this scale.

- How would you rate your own income prospects in the year 2015? Please put a $\sqrt{ }$ on this scale.
$M / F$

years

Yes / No

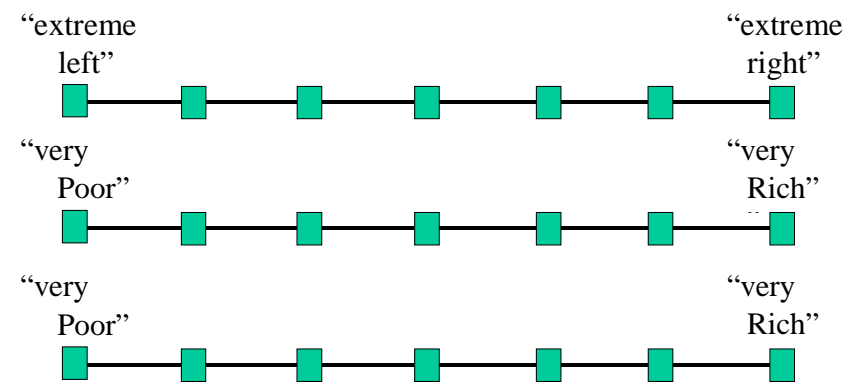




\section{INCOME POLARISATION QUESTIONNAIRE}

This questionnaire concerns people's attitude to income polarisation. We would be interested in your views, based on hypothetical situations. Because it is about attitudes there are no "right" answers. Some of the possible answers correspond to assumptions commonly made by economists: but these assumptions may not be good ones. Your responses will help to shed some light on this, and we would like to thank you for your participation. The questionnaire is anonymous. Please do not write your name on it.

Alfaland is a small country for which two economic programmes have been proposed. It is known that the programmes will have an identical effect on the population - except in so far as incomes are concerned (all the people in Alfaland are identical in every respect other than income). In questions 1 to 10 you are asked about two alternative lists of incomes A and B (in Alfaland local currency) which result from each of these programmes. Please state which programme you consider would make the community of Alfaland more polarised by circling A or B. If you consider that each of the programmes would make the community equally polarised then circle both A and B.

1. $\mathrm{A}=(5,10,10,10,10,50,50,50,50,50)$

2. $A=(7,8,10,10,10,50,50,50,50,50)$

3. $A=(10,10,10,10,10,50,50,50,50,60)$

4. $\quad A=(10,10,10,10,10,50,50,50,50,50)$

5. $\quad A=(10,10,10,10,10,50,50,50,50,50)$

6. $\quad A=(10,10,10,10,10,70,70,100,100,100)$

7. $A=(10,10,10,50,50,50,50,90,90,90)$

8. $\mathrm{A}=(10,10,50,50,50,50,50,50,50$, $100,100,100,100,100)$

9. $\mathrm{A}=(5,5,10,10,10,50,50,50,60,60)$

10. $A=(5,5,5,5,5,60,60,60,60,60)$
$B=(10,10,10,10,10,50,50,50,50,50)$

$B=(5,10,10,10,10,50,50,50,50,50)$

$B=(10,10,10,10,10,10,10,10,10,10,50,50$, $50,50,50,50,50,50,60,60)$

$B=(20,20,20,20,20,100,100,100,100,100)$

$B=(20,20,20,20,20,60,60,60,60,60)$

$B=(10,10,10,10,10,90,90,100,100,100)$

$B=(10,10,10,10,10,90,90,90,90,90)$

$B=(50,50,50,50,50,50,50,100,100$, $100,100,100,100,100)$

$B=(10,10,10,10,10,50,50,50,50,50)$

$B=(10,10,10,10,10,50,50,50,50,50)$ 
In each of the questions 11 to 19 you are presented with a hypothetical change and some views about that change. Please circle the letter alongside the view that corresponds most closely to your own. Feel free to add any comments which explain the reason for your choice.

11) Suppose there is a society consisting of two groups of people with many individuals in each group. One of the groups contains identical low-income people while the other group contains identical highincome people. If a few of the low-income individuals see their income drop by half, then:

a) Income polarisation decreases because society is no longer structured in two sharply defined groups

b) Income polarisation remains the same because one or very few individuals do not make any difference.

c) Income polarisation increases because the income difference between the poorest and the richest is now larger.

d) Whether income polarisation increases/decreases/remains the same depends on the level of income

Suppose that instead of a few low-income individuals seeing their income drop by half, a few highincome individuals see their incomes double. Then income polarisation ...

a) decreases.

b) increases.

c) remains unchanged.

d) may move either way, depending on the level of income.

In the light of the above would you want to change your answer to question 1 ? If so please write your new response ("A" or "B" or “A and B") here:

12) Suppose we transfer income from a person who has more income to a person who has less, without changing anyone else's income. The two persons belong either to the poorest $50 \%$ or to the richest $50 \%$, and after the transfer the person who formerly had more still has more. Income polarisation in this society...

a) has fallen because the person doing the transfer is further away after the transfer from the person who was immediately richer.

b) has increased because the two persons involved in the transfer are closer to each other after the transfer.

c) has not changed.

In the light of the above would you want to change your answer to question 2? If so please write your new response (" $A$ " or " $B$ " or " $A$ and $B$ ") here:

In each of the questions 13 to 15, consider a society with only two groups which have different levels of income. All high-income people have the same income and all low-income people also have the same income.

13) Suppose we replicate this society with an exact copy of itself. After the replication, income polarisation

a) increases because there is more people in each group.

b) decreases.

c) remains the same because the percentage of people in each group is the same as before.

In the light of the above would you want to change your answer to question 3 ? If so please write your new response (" $A$ ” or " $B$ ” or " $A$ and $B$ ”) here: 
14) Suppose we double the income of each person in the above society.

a) The two income groups have the same percentage of people and income share, and the relative income difference between the two groups has not changed, so income polarisation remains the same.

b) The income gap between the rich and the poor group has increased, so income polarisation has increased.

c) After doubling incomes the low-income group might have enough money for basic needs, so income polarisation has decreased.

d) Whether income polarisation increases/decreases/remains the same depends on the level of income

In the light of the above would you want to change your answer to question 4 ? If so please write your new response ("A" or " $\mathrm{B}$ " or "A and B") here:

15) Suppose we add the same fixed amount to the incomes of each person in the above society.

a) Income polarisation has fallen because the relative distance between the two groups has decreased.

b) Income polarisation remains the same because the absolute distance between the two groups has not changed.

c) Income polarisation has increased.

d) Whether income polarisation increases/decreases/remains the same depends on the level of income

In the light of the above would you want to change your answer to question 5 ? If so please write your new response ("A" or "B" or "A and B") here:

16) Consider a society with only three income groups where all persons within a group have the same income level. The first group is the most populated one and has the lowest income level. The second group is less populated than the first one but has the highest income level. The third group is the least populated one and has an intermediate income level, closer to the highest income level of the second group than to the lowest income level of the first group. Suppose we add some income to each person belonging to the third group.

a) Income polarisation increases because the third group is closer to the second group and further away from the first one, so the two least populated groups become closer to each other.

b) Income polarisation falls.

c) Income polarisation remains unchanged.

d) Whether income polarisation increases/decreases/remains the same depends on the levels of income in each group

In the light of the above would you want to change your answer to question 6? If so please write your new response ("A" or " $\mathrm{B}$ " or "A and B") here:

17) Consider a society with three income groups with similar population shares and where all persons within a group have the same income level. Suppose that half the population of the intermediate group moves to the lowest-income group and the other half moves to the highest-income one.

a) As the intermediate group disappears income polarisation increases

b) As the number of groups is smaller, income polarisation falls.

c) Income polarisation remains unchanged.

d) Whether income polarisation increases/decreases/remains the same depends on the levels of income in each group.

In the light of the above would you want to change your answer to question 7? If so please write your new response (" $\mathrm{A}$ " or " $\mathrm{B}$ " or "A and B") here: 
18) Consider a society with three income groups where all persons within a group have the same income level: the income gap between those in the lowest income group and the middle group is about the same as the gap between those in the middle group and the highest income group. The lowest income group has a very small population; the middle group has a very large population. Suppose we add to the incomes of lowest-income group people an amount that is so large that they are lifted to the level of the high-income group.

a) Income polarisation increases because there are now two sharply defined groups.

b) Income polarisation decreases because the lowest income group disappears.

c) Income polarisation does not change.

In the light of the above would you want to change your answer to question 8? If so please write your new response (“A” or "B” or “A and B") here:

19) Consider a society consisting of two groups of people with many individuals in each group. One of the groups contains identical low-income people while the other group contains identical high-income people. Suppose that one by one, low-income individuals become equally poorer and high-income individuals become equally richer. When half of the individuals have moved away from the original groups, the society has four income groups, and as individuals keep on moving the society ends up having once again two groups of identical poorer and richer people.

a) Income polarisation increases continuously because persons are systematically moving further away from each other

b) Income polarisation decreases continuously

c) Income polarisation at first increases and then decreases because at first the number of groups doubles and then halves.

d) Income polarisation at first decreases and then increases because at first the number of groups doubles and then halves.

e) Income polarisation remains the same throughout

f) None of the above.

In the light of the above would you want to change your answer to questions 1,9 and 10 ? If so please write your new responses here:

1:

9:

10:

Finally, we would be grateful for some information about yourself:

- $\quad$ Are you male or female?

- What is your age?

- What is your special subject of study?

- Were you employed before university?

- How would you rate your political views? Please put a $\sqrt{ }$ on this scale.

- How would you rate your family's income in 1995? Please put a $\sqrt{ }$ on this scale.

- How would you rate your own income prospects in the year 2015? Please put a $\sqrt{ }$ on this scale.
$M / F$

years

Yes / No

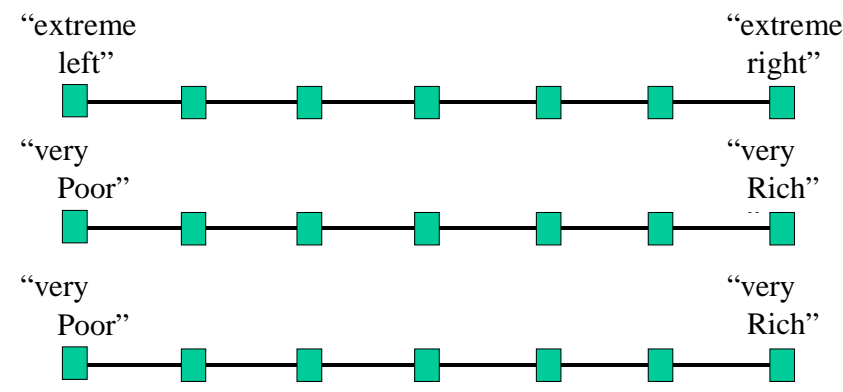




\section{INCOME POLARISATION QUESTIONNAIRE}

This questionnaire concerns people's attitude to income polarisation. We would be interested in your views, based on hypothetical situations. Because it is about attitudes there are no "right" answers. Some of the possible answers correspond to assumptions commonly made by economists: but these assumptions may not be good ones. Your responses will help to shed some light on this, and we would like to thank you for your participation. The questionnaire is anonymous. Please do not write your name on it.

Alfaland is a small country for which two economic programmes have been proposed. It is known that the programmes will have an identical effect on the population - except in so far as incomes are concerned (all the people in Alfaland are identical in every respect other than income). In the pictogram questions 1 to 10 you are asked about two alternative lists of incomes A and B (in Alfaland local currency) which result from each of these programmes. Please state which programme you consider would make the community of Alfaland more polarised by ticking the appropriate box. 
1: $A=(5,10,10,10,10,50,50,50,50,50)$

$B=(10,10,10,10,10,50,50,50,50,50)$

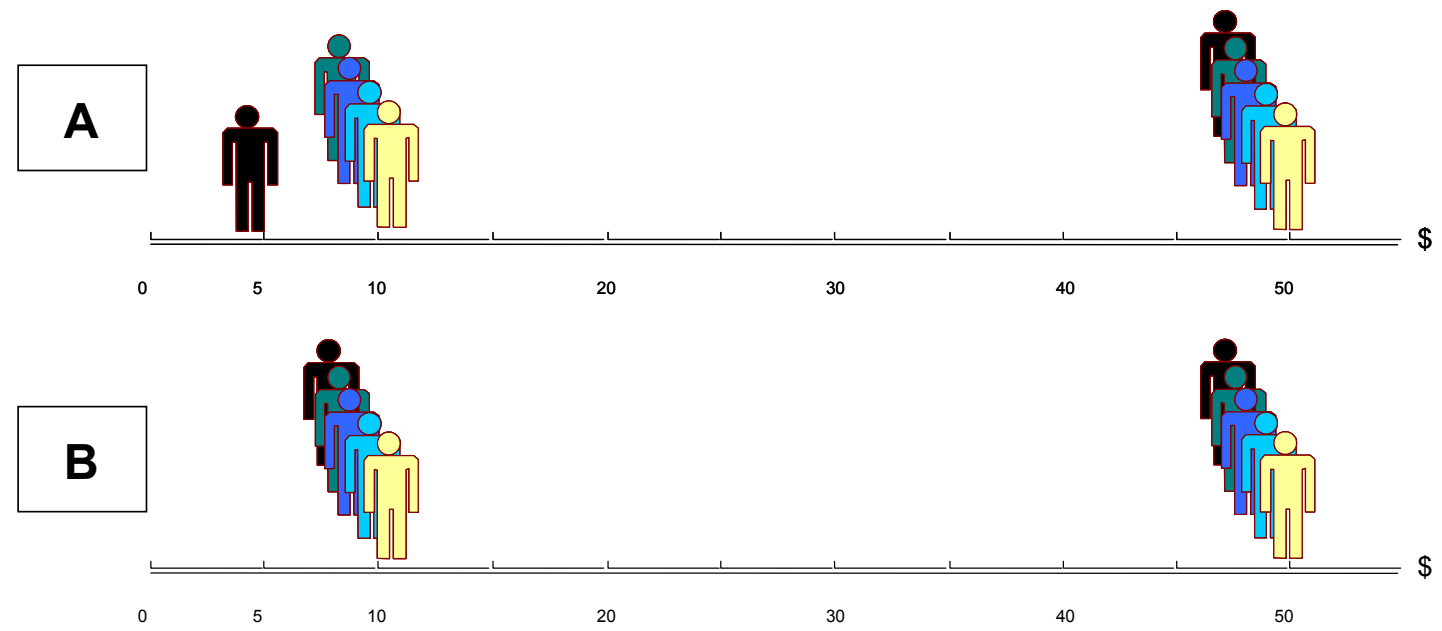

Please check $(\checkmark)$ one: A is more polarised

$\mathrm{B}$ is more polarised

polarisation is the same in A and B

\section{2: $A=(7,8,10,10,10,50,50,50,50,50)$ \\ $B=(5,10,10,10,10,50,50,50,50,50)$}
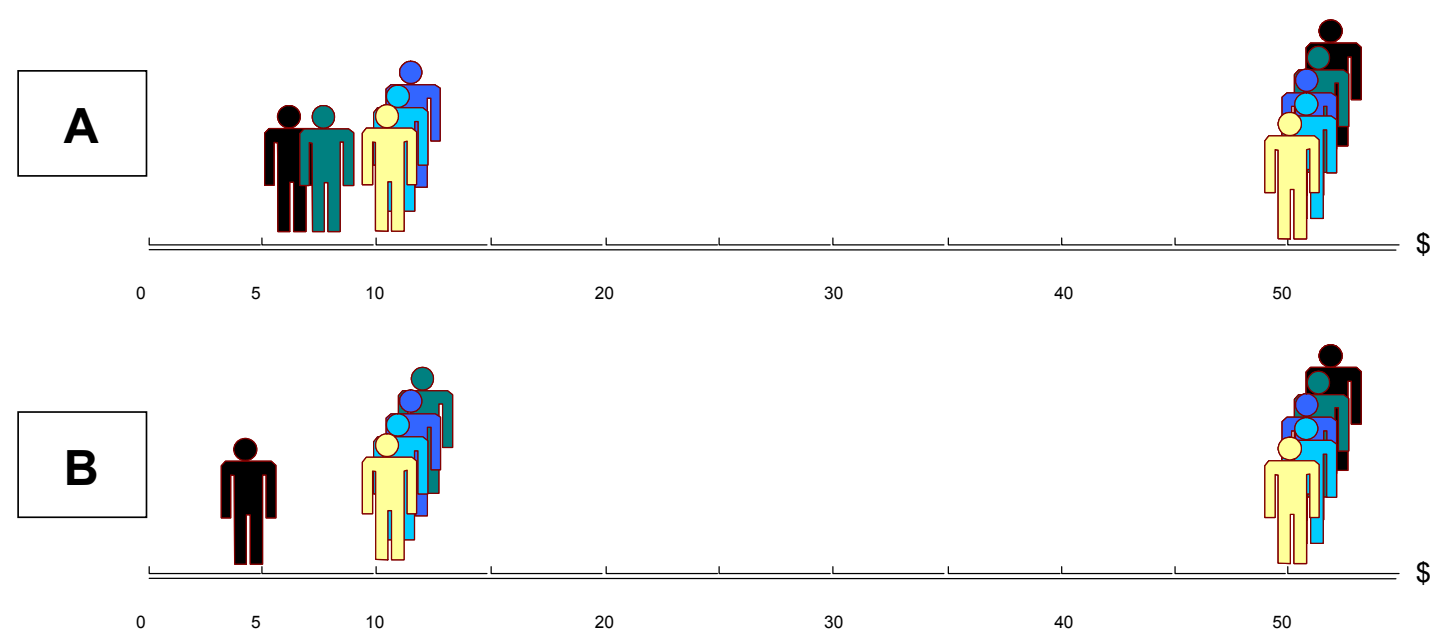

Please check ( $\checkmark$ ) one: A is more polarised

$\mathrm{B}$ is more polarised

polarisation is the same in A and B 
3:

$A=(10,10,10,10,10,50,50,50,50,60)$

$B=(10,10,10,10,10,10,10,10,10,10,50,50,50,50,50,50,50,50,60,60)$

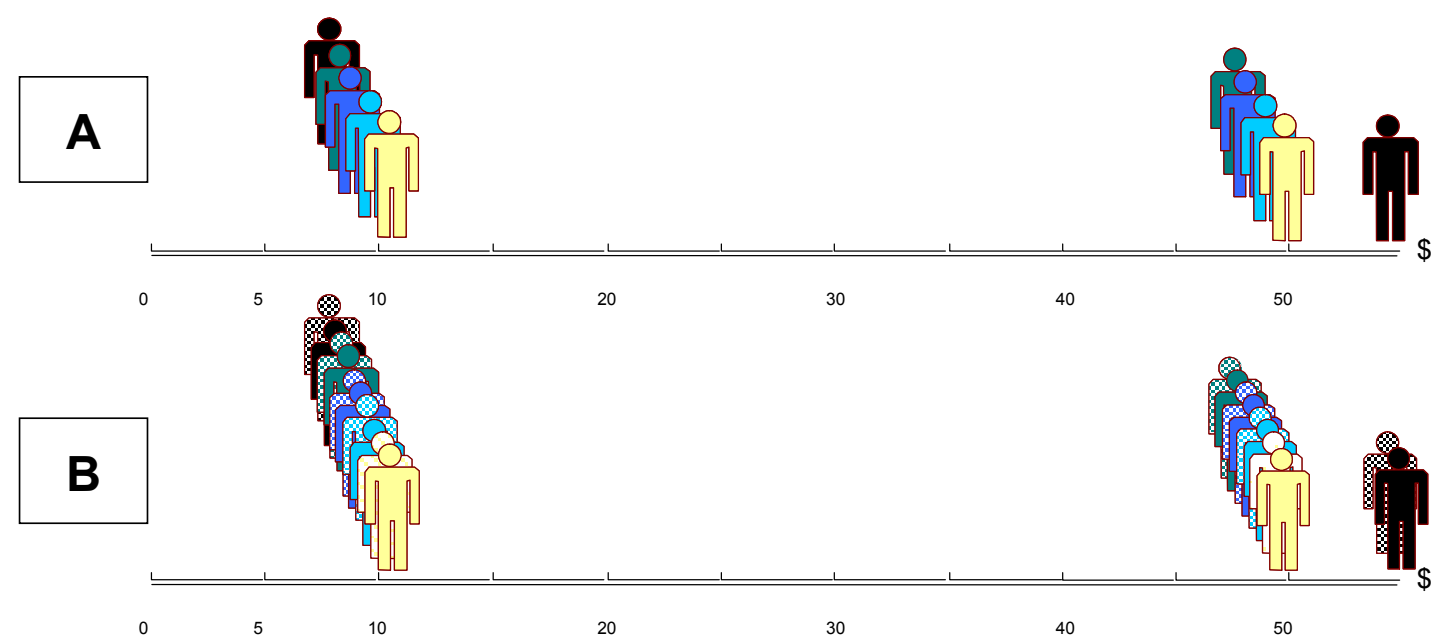

Please check $(\checkmark)$ one: A is more polarised

$\mathrm{B}$ is more polarised

polarisation is the same in A and B

\section{4: $A=(10,10,10,10,10,50,50,50,50,50)$ \\ $B=(20,20,20,20,20,100,100,100,100,100)$}
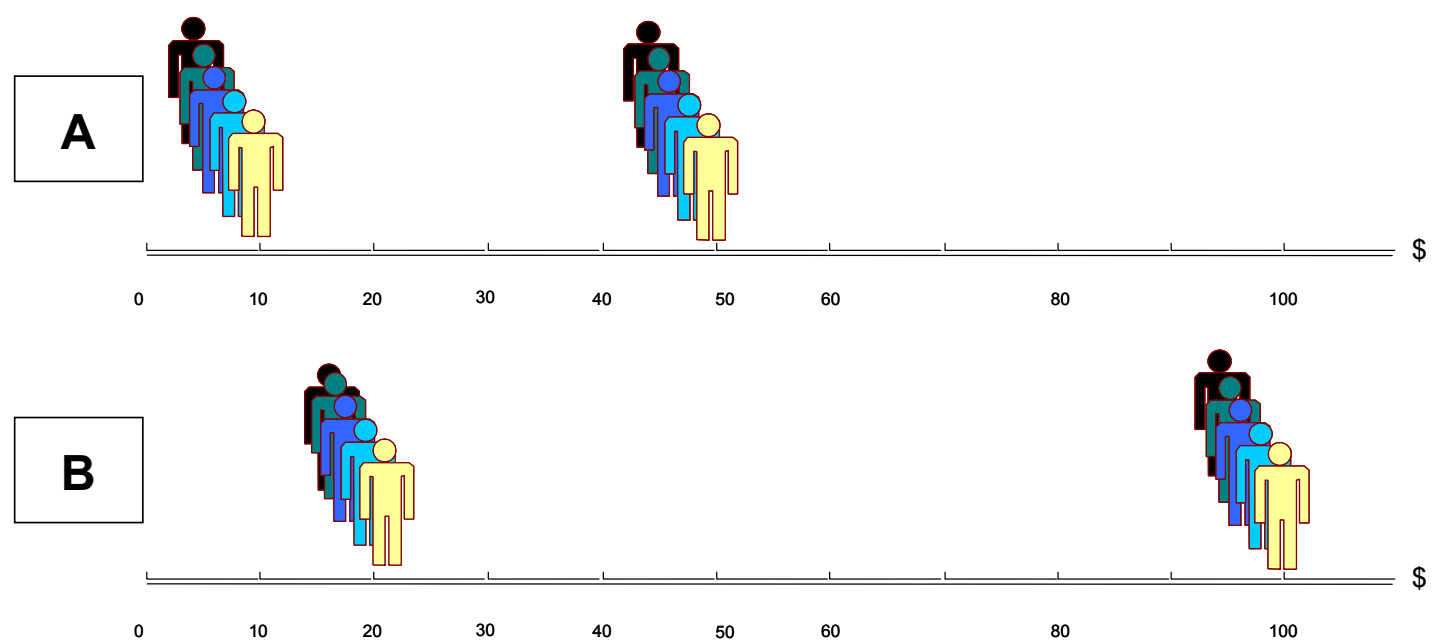

Please check $(\checkmark)$ one: $\quad$ A is more polarised

$\mathrm{B}$ is more polarised

polarisation is the same in A and B 


\section{5: $A=(10,10,10,10,10,50,50,50,50,50)$ $B=(20,20,20,20,20,60,60,60,60,60)$}

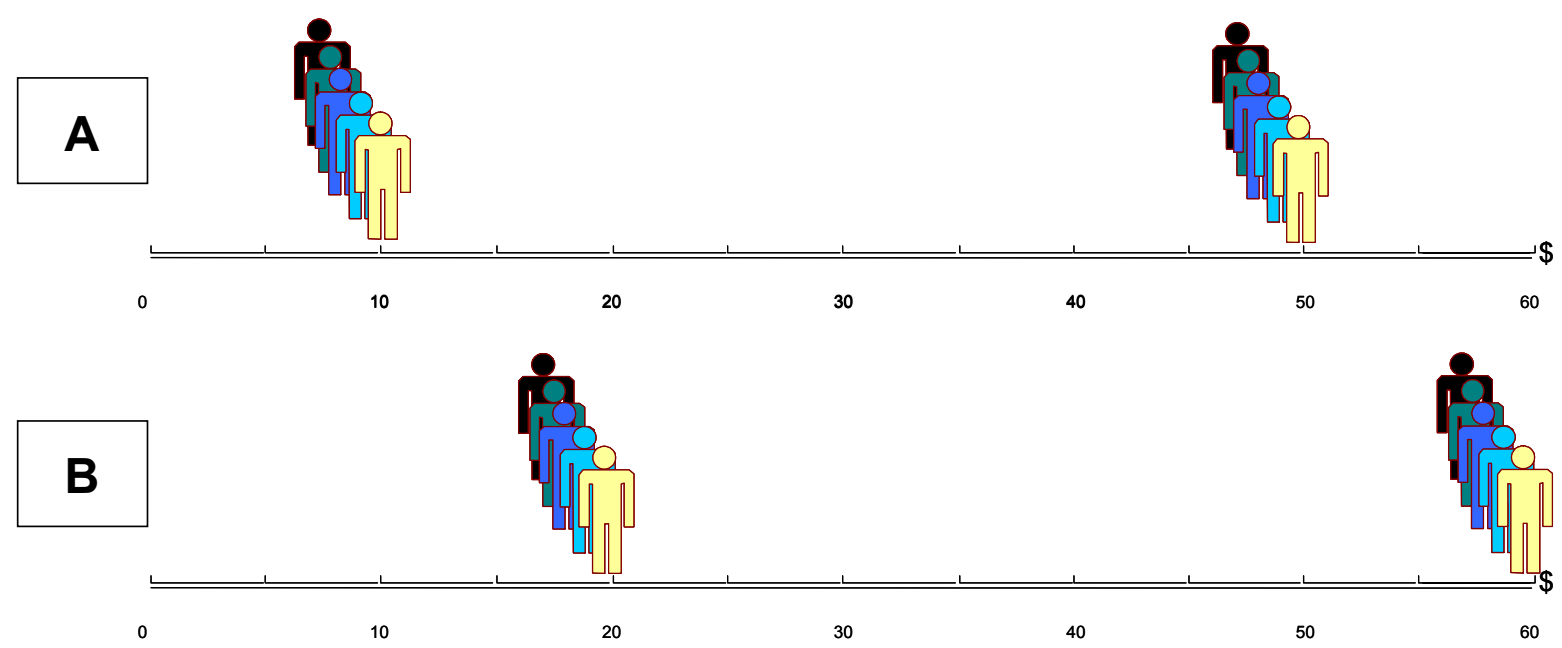

Please check $(\checkmark)$ one: $\quad$ A is more polarised $\mathrm{B}$ is more polarised polarisation is the same in A and B

\section{6: $A=(10,10,10,10,10,70,70,100,100,100)$ $B=(10,10,10,10,10,90,90,100,100,100)$}
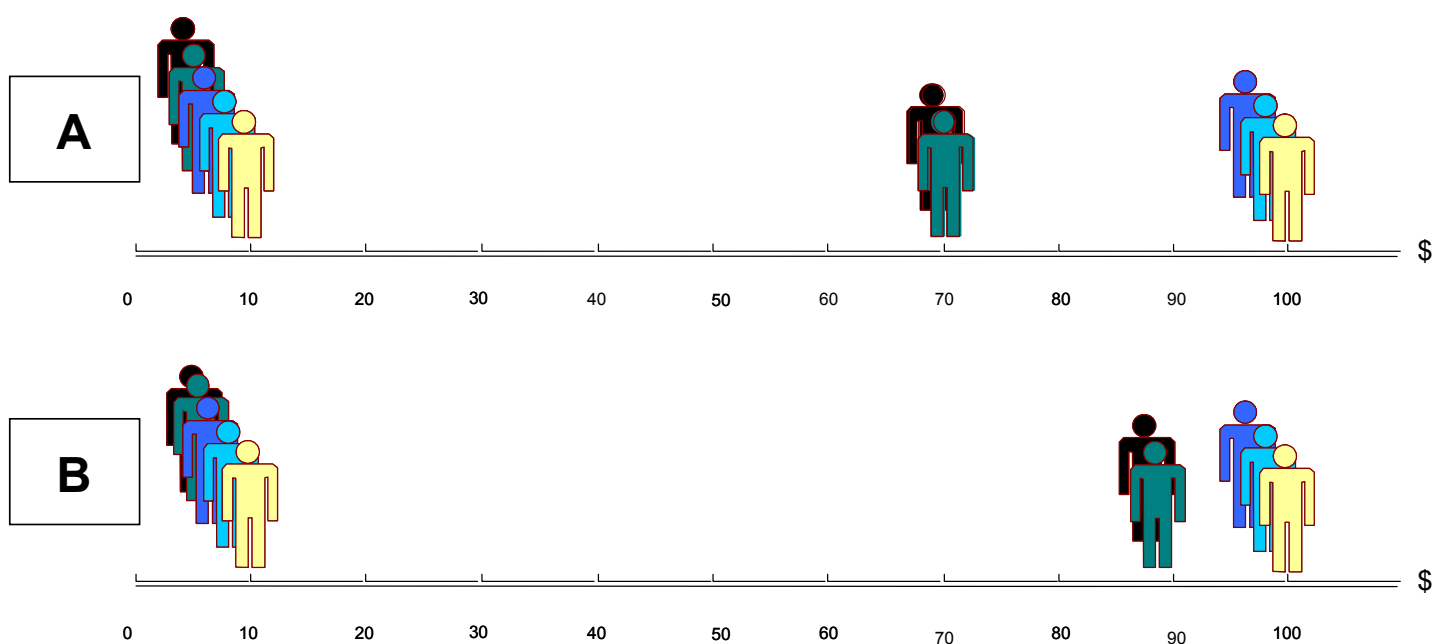

Please check $(\checkmark)$ one: $\quad$ A is more polarised

$\mathrm{B}$ is more polarised polarisation is the same in A and B 


\section{7: $A=(10,10,10,50,50,50,50,90,90,90)$ \\ $B=(10,10,10,10,10,90,90,90,90,90)$}

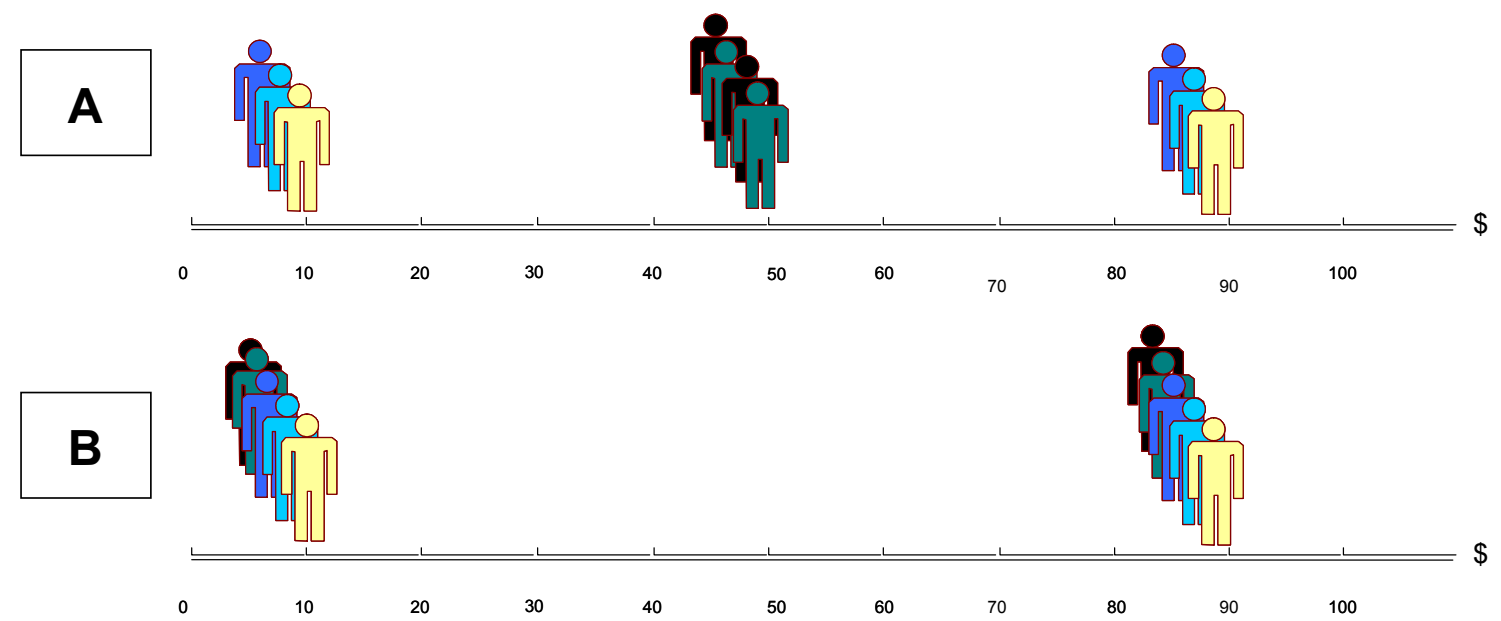

Please check $(\boldsymbol{\checkmark})$ one: $\quad$ A is more polarised

$\mathrm{B}$ is more polarised

polarisation is the same in $\mathrm{A}$ and $\mathrm{B}$

\section{$8: A=(10,10,50,50,50,50,50,50,50,100,100,100,100,100)$ $B=(50,50,50,50,50,50,50,100,100,100,100,100,100,100)$}

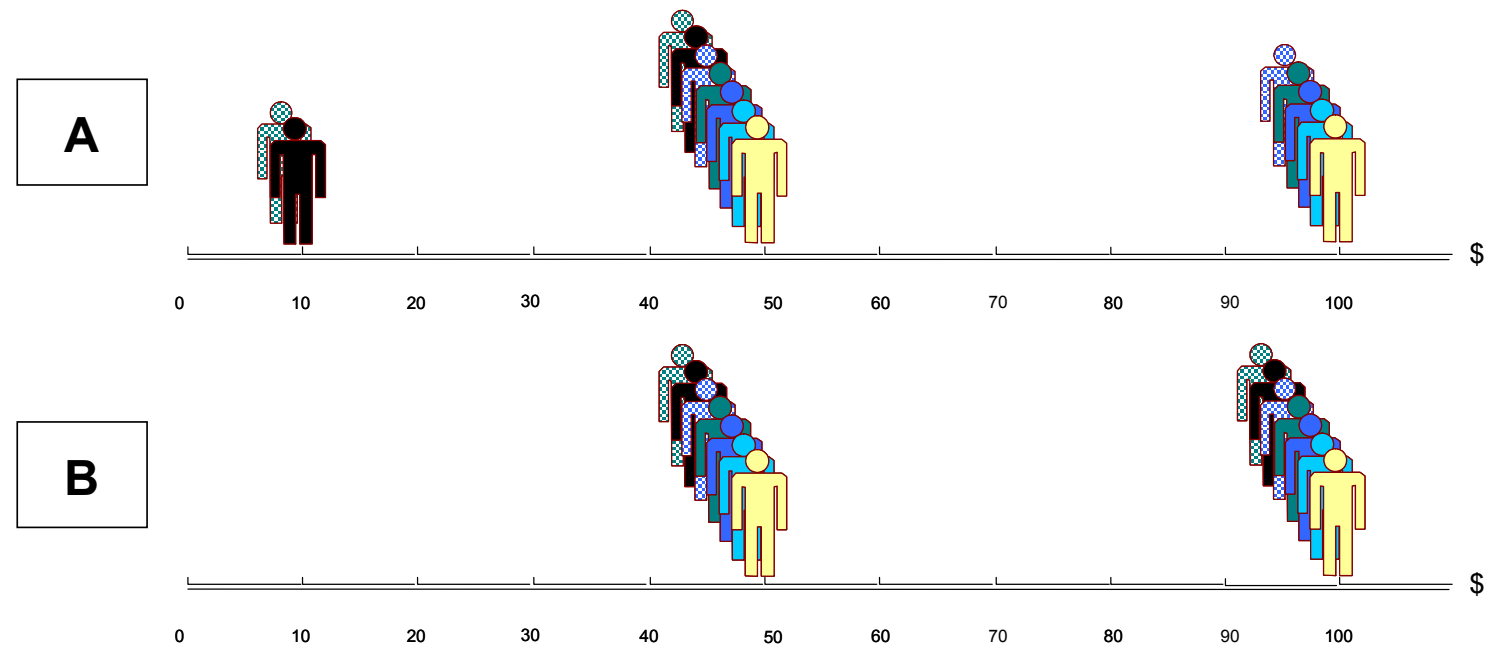

Please check $(\checkmark)$ one: $\quad$ A is more polarised $\mathrm{B}$ is more polarised polarisation is the same in $\mathrm{A}$ and $\mathrm{B}$ 


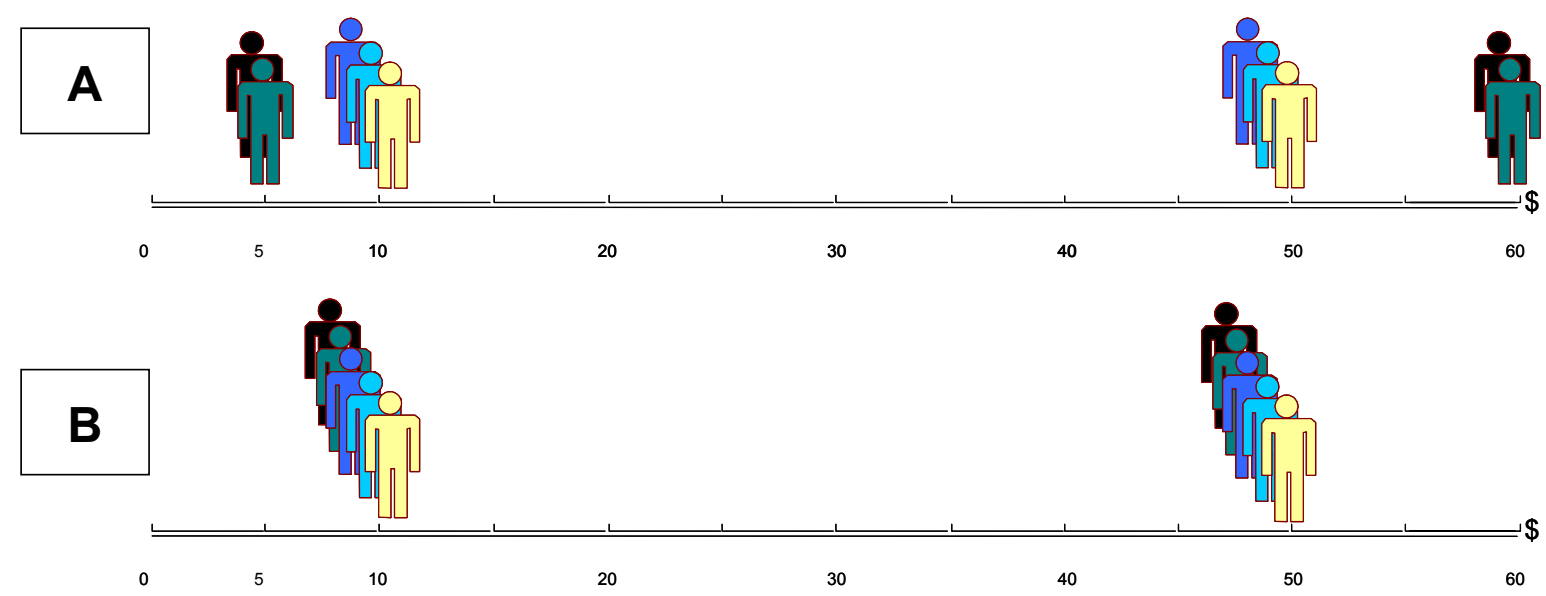

Please check $(\checkmark)$ one: $\quad$ A is more polarised $\mathrm{B}$ is more polarised polarisation is the same in A and B

\section{0: $A=(5,5,5,5,5,60,60,60,60,60)$ $B=(10,10,10,10,10,50,50,50,50,50)$}

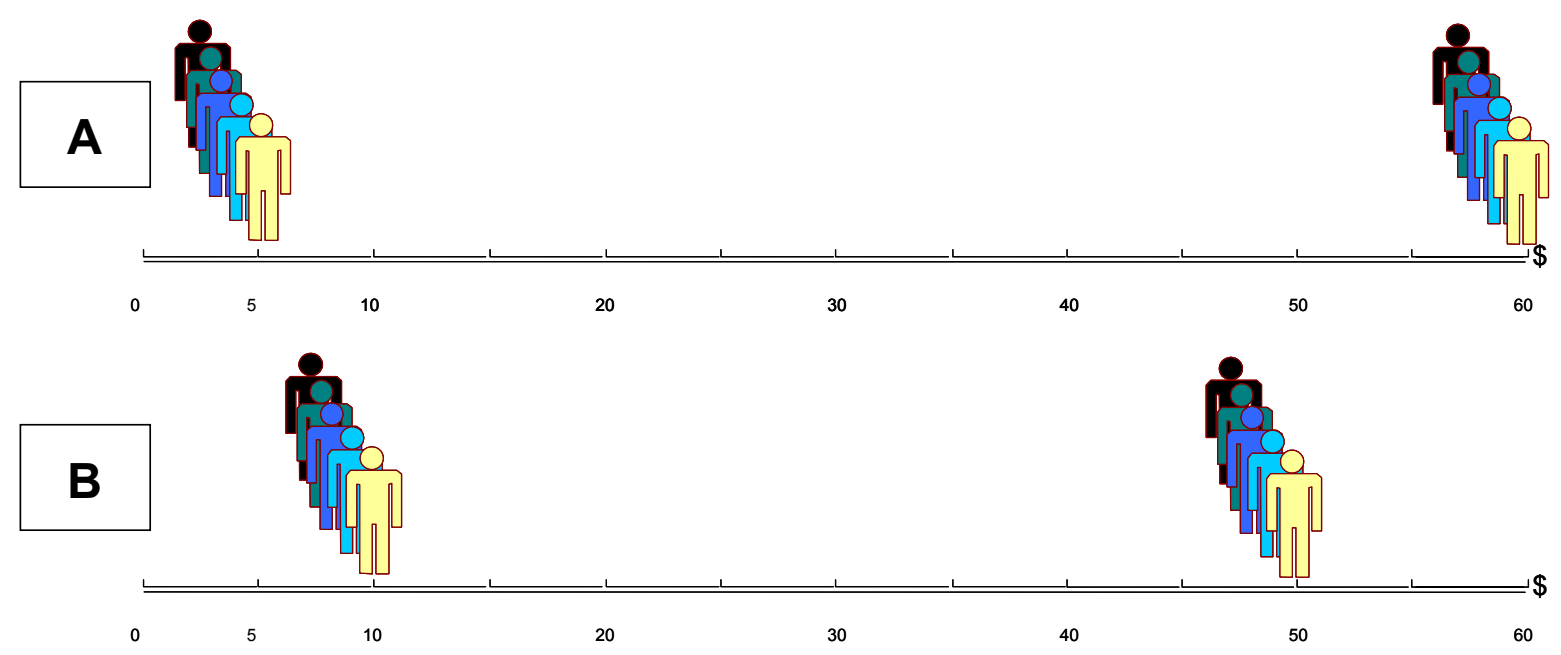

Please check $(\checkmark)$ one: $\quad$ A is more polarised $\mathrm{B}$ is more polarised polarisation is the same in A and B 
In each of the questions 11 to 19 you are presented with a hypothetical change and some views about that change. Please circle the letter alongside the view that corresponds most closely to your own. Feel free to add any comments which explain the reason for your choice.

11) Suppose there is a society consisting of two groups of people with many individuals in each group. One of the groups contains identical low-income people while the other group contains identical highincome people. If a few of the low-income individuals see their income drop by half, then:

a) Income polarisation decreases because society is no longer structured in two sharply defined groups

b) Income polarisation remains the same because one or very few individuals do not make any difference.

c) Income polarisation increases because the income difference between the poorest and the richest is now larger.

d) Whether income polarisation increases/decreases/remains the same depends on the level of income

Suppose that instead of a few low-income individuals seeing their income drop by half, a few highincome individuals see their incomes double. Then income polarisation ...

a) decreases.

b) increases.

c) remains unchanged.

d) may move either way, depending on the level of income.

In the light of the above would you want to change your answer to question 1 ? If so please write your new response ("A" or "B" or “A and B") here:

12) Suppose we transfer income from a person who has more income to a person who has less, without changing anyone else's income. The two persons belong either to the poorest $50 \%$ or to the richest $50 \%$, and after the transfer the person who formerly had more still has more. Income polarisation in this society...

a) has fallen because the person doing the transfer is further away after the transfer from the person who was immediately richer.

b) has increased because the two persons involved in the transfer are closer to each other after the transfer.

c) has not changed.

In the light of the above would you want to change your answer to question 2? If so please write your new response (" $A$ " or " $B$ " or " $A$ and $B$ ") here:

In each of the questions 13 to 15, consider a society with only two groups which have different levels of income. All high-income people have the same income and all low-income people also have the same income.

13) Suppose we replicate this society with an exact copy of itself. After the replication, income polarisation

a) increases because there is more people in each group.

b) decreases.

c) remains the same because the percentage of people in each group is the same as before.

In the light of the above would you want to change your answer to question 3 ? If so please write your new response (" $A$ ” or " $B$ ” or " $A$ and $B$ ”) here: 
14) Suppose we double the income of each person in the above society.

a) The two income groups have the same percentage of people and income share, and the relative income difference between the two groups has not changed, so income polarisation remains the same.

b) The income gap between the rich and the poor group has increased, so income polarisation has increased.

c) After doubling incomes the low-income group might have enough money for basic needs, so income polarisation has decreased.

d) Whether income polarisation increases/decreases/remains the same depends on the level of income

In the light of the above would you want to change your answer to question 4? If so please write your new response ("A" or " $\mathrm{B}$ " or "A and B") here:

15) Suppose we add the same fixed amount to the incomes of each person in the above society.

a) Income polarisation has fallen because the relative distance between the two groups has decreased.

b) Income polarisation remains the same because the absolute distance between the two groups has not changed.

c) Income polarisation has increased.

d) Whether income polarisation increases/decreases/remains the same depends on the level of income

In the light of the above would you want to change your answer to question 5 ? If so please write your new response ("A" or " $\mathrm{B}$ " or "A and B") here:

16) Consider a society with only three income groups where all persons within a group have the same income level. The first group is the most populated one and has the lowest income level. The second group is less populated than the first one but has the highest income level. The third group is the least populated one and has an intermediate income level, closer to the highest income level of the second group than to the lowest income level of the first group. Suppose we add some income to each person belonging to the third group.

a) Income polarisation increases because the third group is closer to the second group and further away from the first one, so the two least populated groups become closer to each other.

b) Income polarisation falls.

c) Income polarisation remains unchanged.

d) Whether income polarisation increases/decreases/remains the same depends on the levels of income in each group

In the light of the above would you want to change your answer to question 6? If so please write your new response ("A" or " $\mathrm{B}$ " or "A and B") here:

17) Consider a society with three income groups with similar population shares and where all persons within a group have the same income level. Suppose that half the population of the intermediate group moves to the lowest-income group and the other half moves to the highest-income one.

a) As the intermediate group disappears income polarisation increases

b) As the number of groups is smaller, income polarisation falls.

c) Income polarisation remains unchanged.

d) Whether income polarisation increases/decreases/remains the same depends on the levels of income in each group.

In the light of the above would you want to change your answer to question 7? If so please write your new response (" $\mathrm{A}$ " or " $\mathrm{B}$ " or "A and B") here: 
18) Consider a society with three income groups where all persons within a group have the same income level: the income gap between those in the lowest income group and the middle group is about the same as the gap between those in the middle group and the highest income group. The lowest income group has a very small population; the middle group has a very large population. Suppose we add to the incomes of lowest-income group people an amount that is so large that they are lifted to the level of the high-income group.

a) Income polarisation increases because there are now two sharply defined groups.

b) Income polarisation decreases because the lowest income group disappears.

c) Income polarisation does not change.

In the light of the above would you want to change your answer to question 8? If so please write your new response (“A” or "B” or “A and B") here:

19) Consider a society consisting of two groups of people with many individuals in each group. One of the groups contains identical low-income people while the other group contains identical high-income people. Suppose that one by one, low-income individuals become equally poorer and high-income individuals become equally richer. When half of the individuals have moved away from the original groups, the society has four income groups, and as individuals keep on moving the society ends up having once again two groups of identical poorer and richer people.

a) Income polarisation increases continuously because persons are systematically moving further away from each other

b) Income polarisation decreases continuously

c) Income polarisation at first increases and then decreases because at first the number of groups doubles and then halves.

d) Income polarisation at first decreases and then increases because at first the number of groups doubles and then halves.

e) Income polarisation remains the same throughout

f) None of the above.

In the light of the above would you want to change your answer to questions 1,9 and 10 ? If so please write your new responses here:

1:

9:

10:

Finally, we would be grateful for some information about yourself:

- $\quad$ Are you male or female?

- What is your age?

- What is your special subject of study?

- Were you employed before university?

- How would you rate your political views? Please put a $\sqrt{ }$ on this scale.

- How would you rate your family's income in 1995? Please put a $\sqrt{ }$ on this scale.

- How would you rate your own income prospects in the year 2015? Please put a $\sqrt{ }$ on this scale.
$M / F$

years

Yes / No

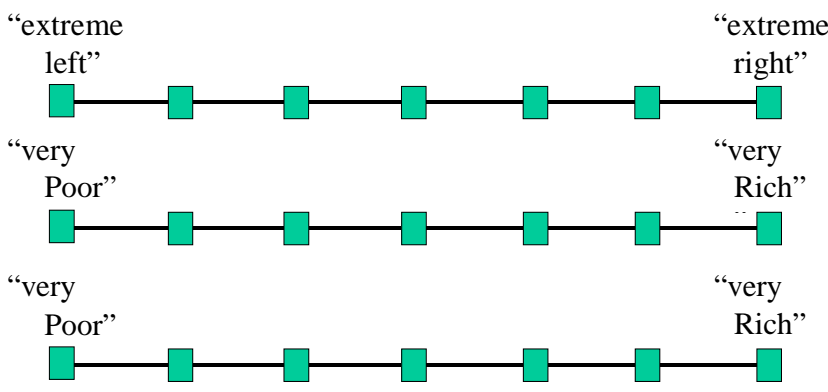

Thanks once again for your help! 